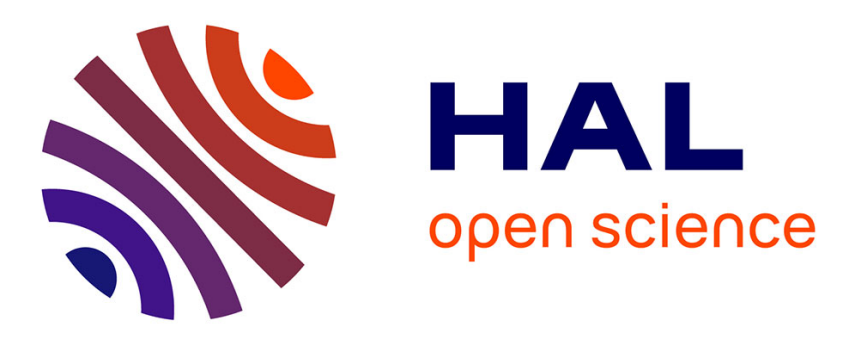

\title{
Nanoscience with non-equilibrium plasmas at atmospheric pressure
}

Thierry Belmonte, G Arnoult, G Henrion, T Gries

\section{To cite this version:}

Thierry Belmonte, G Arnoult, G Henrion, T Gries. Nanoscience with non-equilibrium plasmas at atmospheric pressure. Journal of Physics D: Applied Physics, 2011, 44 (36), pp.363001. 10.1088/0022$3727 / 44 / 36 / 363001$. hal-00651636

\section{HAL Id: hal-00651636 https://hal.science/hal-00651636}

Submitted on 14 Dec 2011

HAL is a multi-disciplinary open access archive for the deposit and dissemination of scientific research documents, whether they are published or not. The documents may come from teaching and research institutions in France or abroad, or from public or private research centers.
L'archive ouverte pluridisciplinaire HAL, est destinée au dépôt et à la diffusion de documents scientifiques de niveau recherche, publiés ou non, émanant des établissements d'enseignement et de recherche français ou étrangers, des laboratoires publics ou privés. 


\section{NANOSCIENCE WITH NON-EQUILIBRIUM PLASMAS AT ATMOSPHERIC PRESSURE}

T Belmonte* G Arnoult G Henrion T Gries

Institut Jean Lamour, Department of Chemistry and Physics of Solids and Surfaces, NancyUniversité, CNRS, Parc de Saurupt, CS 14234, F-54042 Nancy Cedex, France

* Corresponding author

Fax : +33 383534764

E-mail : thierry.belmonte@mines.inpl-nancy.fr

PACS number: $\quad$ 81.16.-c $\quad$ Methods of nanofabrication and processing

52.77.-j Plasma applications

Keywords: atmospheric pressure plasma ; microplasma ; nanoscience 


\begin{abstract}
This review devoted to nanoscience with atmospheric pressure plasmas shows how nanomaterials are synthesised locally using three main ways: localized PECVD, nanoparticles and templates. On the other hand, self-organization of nano-objects on surfaces is driven by electric fields, stress and high temperatures. We show that the specificities of plasmas at high pressure, as their small size, their self-organization or their filamentation have been little exploited in the synthesis of nanomaterials. Finally, perspectives in the field are given.
\end{abstract}




\section{Introduction}

After the development of micro-discharges that resulted from the renewed interest in plasmas generated at atmospheric pressure, many attempts were made to grow nanostructures on surfaces without vacuum [1-5]. The first nanostructures were built by mimicking the methods adopted to grow carbon nanotubes under vacuum [6-10]. These original approaches consisted in utilizing atmospheric plasmas that are much easier to implement on industrial production lines in order to reproduce results obtained in low-pressure conditions.

The development of micro-plasmas has strongly contributed in reorienting works towards applications where a localized treatment is necessary. One of the best example is certainly plasma treatment for biomedical applications where the possibility to operate at atmospheric pressure opens up new perspectives [11-16].

Treatments at atmospheric pressure have specific characteristics. For example, cold plasmas at atmospheric pressure differ from cold plasmas under vacuum by weak laminar diffusion fluxes that are most often negligible compared to other fluxes of transfer of matter. Increasing the pressure gives rise spontaneously to plasma filaments of small dimensions [17-20]. Then, plasmas at atmospheric pressure have features that cannot be found in low-pressure plasmas. We shall endeavour to illustrate how these features can be advantageously used in the field of nanoscience and nanotechnology.

Several important topical reviews [21-34] were proposed over the last decade to give brilliant overviews of plasma nanoscience. Some focussed on specific materials like carbon and its various forms [21, 22, 24, 29] or semi-conductor nanocrystals [28]. Ostrikov et al. emphasized the specificity not only of low-pressure plasmas [23, 25-27, 32-34] but also of thermal plasmas [26]. Finally, two excellent papers written by Mariotti and Sankaran [30, 35] discuss some features of microplasmas for nanomaterials synthesis. The present review aims 
to complete these works and more specifically the last ones by detainling strategies to grow nanostructures with non-equilibrium plasmas at atmospheric pressure.

In this work, we introduce two general approaches. In the first one, self-organized nanostructures grow on surfaces as parts of a coating deposited at larger scale by plasma. Such an approach was first proposed under vacuum [26-39], and more recently at atmospheric pressure [40-43]. Matter gets organized spontaneously on the substrate and, under the effect of the plasma, produces architectures of nanometric objects. In the second approach, the possibility to grow an isolated nanometric object from atmospheric plasmas and eventually to assemble several of these elementary units into given architectures was described by several groups [44-47], with modest, yet undeniable, success. To date, all the achievements made with this second approach are micrometric, but recent developments on plasmas in or on liquids [48] suggest that it would be possible to reach the nanometre scale. Indeed, liquid interfaces or media could be used to scale down processes where cold plasmas at atmospheric pressure already allows experimentalists to synthesise micrometric objects. For example, it is possible to determine locally, i.e. over distances limited to several hundreds of nanometres, the composition of a liquid by creating a plasma with a nanotube electrode and by observing it by optical emission spectroscopy [49].

We propose to establish an overview of the state-of-the-art nanoscience based on cold plasmas at atmospheric pressure. This article is structured as follows. In section 2, we present a general overview of the different plasma sources used in the two approaches described previously for growing nanostructures on a surface. In section 3, we describe the three ways that are adopted to grow an isolated nanometric object on a surface. In section 4, we discuss two main ways to get self-organized nanostructures. The article concludes with a summary of the main challenges ahead and the outlook for the future research in the field.

\section{Plasma sources at atmospheric pressure for nanostructures}


Plasma sources used to grow nanostructures are very heterogeneous in terms of gas temperature, electron temperature, active species density, etc. Categorising them is not an easy task. Roughly, we can distinguish three types of sources: Large Area Dielectric Barrier Discharges, Microplasma jets and plasma torches. This presentation suffers from a lack of consistency since specificities of each type of sources can be found in another type. For example, microplasma jets can be dielectric barrier discharges. However, this classification is generally adopted by the authors themselves and it will be kept here on purpose. Indeed, we shall not review in this part the physics of these sources which can be found elsewhere (for dielectric barrier discharges, see $[1,50,51]$; for microplasma jets, see $[2,6,52,53]$; for plasma torches see [54] ; and [55] for a general overview). We shall give only the main specificities that are looked for when one wishes to use these sources in nanoscience.

\subsection{Large Area Dielectric Barriers Discharges}

Dielectric Barrier Discharges are low temperature plasmas that can be used to treat large areas. A DBD device consists of two parallel metal electrodes, at least one of which being covered by a dielectric layer (figure 1a - after Jiang et al. [44]). To ensure stable operation, the gap which separates the electrodes is limited to a few millimetres wide. The discharge is sustained by a sinusoidal or a pulsed electric field. Depending on the composition of the working gas, the voltage and the frequency excitation, the discharge can be either filamentary or glow. A filamentary discharge is a set of micro-discharges or streamers more or less randomly distributed over the dielectric surface. One key issue of Dielectric Barrier Discharges used for material processing is the distribution of these streamers as a function of time. Different mechanisms were identified showing that preferential conditions can be encountered to reignite a streamer on a spot just hit by a previous streamer. For instance, periodic patterns like hexagon structure and stripe structure have been observed in DBD due to short-range interactions between streamers. The non-uniformity caused by the filamentary 
nature of the discharge can be turned into an advantage as described later. However, no selforganized pattern of streamers was used for nanoscience purposes.

Important efforts were made to produce atmospheric pressure glow discharges. However, special conditions must be fulfilled to get a homogenous discharge like the addition of helium or nitrogen in the discharge and the use of millimetre gaps. Basically, the avalanche-tostreamer transition can be avoided by increasing the avalanche radius and by providing sufficient pre-ionization [56]. Helium and nitrogen are gases which favour this phenomenon and therefore, glow discharges. These glow discharges, as such, have been used to grow carbon nanotubes [57] and silicon nanoparticles [58]. Associated with cyclone system, they can be run to coat particles $[59,60]$. They are certainly used by default in DBD microplasma jets where gaps are extremely small (down to $100 \mu \mathrm{m})$.

The electron density of atmospheric pressure glow discharges lies between $10^{9}$ and $10^{13} \mathrm{~cm}^{-3}$. In non-uniform discharges, it lies rather between $10^{14}$ and $10^{15} \mathrm{~cm}^{-3}$. To increase the plasma density, "pin-to-plate" arrangements and dielectric barrier with capillary holes were proposed (figure 1b-e). Pin-to-plate dielectric barrier discharges [61] are composed of a multi-pin power electrode. Such sources were developed to generate high density plasmas with low breakdown voltage [62]. The pin shape enhances the applied local electric field. Substrates can be processed in direct plasma (figure $1 \mathrm{~b}$ after [63]). However, to avoid the non-uniformity caused by the filamentary nature of the discharge, another source was designed to operate in the remote mode [64]. In this case, the power electrode is made of aluminium and machined to have multi-pins with a pyramid shape, as shown in figure 1c (after [65]). Electrodes are coated with $300 \mu \mathrm{m}$ thick alumina to have the dielectric barrier. Another solution was proposed by Kyung et al. [66]. A dielectric barrier with capillary holes was preferred (figure 1d) to get a more uniform reactive gas distribution compared to conventional dielectric barrier discharges. It also produces a higher plasma density due to ion-beam like plasmas created in 
holes. Another configuration based on the same idea was proposed by Jiang et al. [67] (figure 1e). A grid electrode made of stainless steel, much easier to machine than the dielectric material, is placed between the dielectric barrier and the substrate. It turns out that high density plasmas with high uniformity are usually preferred to grow nanostructures.

\subsection{Microplasma jets}

Microplasma jets can be created by any excitation mode (dc [68], rf [45], microwave [46, 47]). They can be processed directly or in a remote mode, continuously or in a pulsed regime. Basically, a low total energy is deposited into a localized small space, making possible the control of the heat flux, a necessary condition to fulfil to preserve the materials integrity. A fine plasma jet at high temperature but with low total energy can be created. This principle rules the behaviour of the microplasma jets that differ strongly from plasma torches where the local thermodynamic equilibrium prevails.

Three important items concerning microplasma jets have to be addressed:

- the use of a capillary to localize the flow of at least one precursor,

- the use of wires as consumable sources of matter,

- the excitation mode (dc, rf, microwave) and the way the electric field is applied, which may influence the growth of nano-objects.

The first point deals with the location of one of the two reactive precursors through capillaries. Currently, most methods based on the use of capillaries can locate the deposition area over a few thousands of square micrometers (the distribution in thickness generally encountered is Gaussian and its full width at half maximum gives the diameter of the deposition area). Capillaries are obtained by pulling a micropipette commonly made of fused silica. When the inner diameter of the capillary is reduced, the total gas flow must be adapted to avoid a strong increase in the upstream pressure. 
Resorting to consumable wires can be seen as a way to synthesise vapours or nanoparticles that are the precursors of the nanostructures to be built. In that sense, any reactive plasma used as a source of nanoparticles plays the same role. One of the most explicit examples based on this idea was first proposed by Ito and Terashima [69] and by Shimizu et al. during the following years $[46,47,70-72]$. The microplasma generator consists of a capillary (100$500 \mu \mathrm{m}$ inner diameter) made of quartz or alumina [72] joined to a metal tube where the gases are injected, and a tungsten wire (50 $\mu \mathrm{m}$ in diameter) inserted into the capillary. This capillary is wound around by a 5-turn coil whose end is connected to a $450 \mathrm{MHz}$ UHF generator (5-30 W) via a matching circuit, while the other end is grounded (figure 2a) [46]. An outer metallic armour must be placed around the process to shield the external components from the high frequency electric field. Plasma ignition is ensured by a $15 \mathrm{kV}$ dc power supply. This original idea underwent several successive changes. The previous setup was first modified with a pinched nozzle (60-70 $\mu \mathrm{m}$ exit inner diameter) made by pulling the quartz capillary $[70,72]$ (figure $2 \mathrm{~b})$. A 20-turn coil made of $\mathrm{Cu}$ wire $(280 \mu \mathrm{m}$ in diameter) was preferred to the previous 5-turn coil. The tungsten wire was replaced by other metallic wires $(50 \mu \mathrm{m}$ in diameter). The choice of the metal is mainly defined by the possibility to get a volatile oxide at the temperature of the neutral species in the plasma. It is defined by the total gas flow rate and the plasma power [73]. This strong link between plasma conditions and production of the source material of the nanostructures is probably the biggest drawback. The problem of the consumption of the wire could be circumvented by using a mechanism to feed the wire continuously.

The last point deals with the excitation mode and the way the electric field is applied. Using the same example, we notice that the distance between the substrate and the wire plays an essential role on the final morphology of the nanostructures. This distance changes with time because the wire is consumed. As shown in reference [71], this consumption is not uniform. 
The control of such a process is quite complex, although it is cheap and relatively easy to build. The energy coupling between the power supply and the plasma depends on the way the wire vaporizes. The influence of the emission of vapours of volatile oxides on the behaviour of the plasma is still to be clarified. The energy coupling also depends on the way the ultra high frequency is applied. A major modification was brought to the previous device by Mariotti et al. [40] when they proposed to remove the coil and to apply directly the UHF signal on a bottom glass epoxy copper plated electrode $\left(2 \times 2 \mathrm{~cm}^{2}\right)$ which acts as a patch antenna (figure 2c). The substrate is placed on top of this electrode. This modification in the power coupling strongly influences the growth of the nanostructures. As explained latter, both the distribution of the surface electric field and the incoming flux of species from the plasma act on the way matter gets organized.

Ichiki et al. [16] and Kikuchi et al. [74] proposed a similar configuration with a rf-plasma (13.56 MHz). For the formers, the plasma is generated inside a capillary (1 mm inner diameter) by applying a $100-\mathrm{MHz}$ VHF power of $200-300 \mathrm{~W}$ to a solenoid antenna (figure 2d). $\mathrm{SF}_{6}$ gas is added to the plasma jet ejected from an annular nozzle (100- $\mu \mathrm{m}$ inner diameter) to produce a high-density etchant flux to the sample surface. For the latters, a needle capillary electrode, made of tungsten carbide $(2 \mathrm{~cm}$ in length and a minimum inner hole diameter of $150 \mu \mathrm{m}$ ) is used as rf-power electrode (figure 2e). This choice influences the energy coupling between the power supply and the plasma. Losses of electrons and negatively charged species at the wall of the needle electrode are described as being the main mechanism that limits the energy transfer. The excitation temperature increases when these losses increase. Consequently, no plasma can be sustained as soon as the oxygen concentration in helium exceeds 5\%. From a practical standpoint, it is convenient to work with microwaves instead of radio-frequency, more difficult to implement to get a stable power matching. It would be certainly possible to use "strip" technology [75-78] to deposit on lines instead of 
spots. However, since erosion of the strips has always been presented as being negligible [7779], the strips could not be used as a consumable material for deposition.

Among other important plasma sources, microplasmas constitutes a promising way to synthesise nanoparticles when they are used as component of an electric circuit where charge conduction occurs through a liquid $[30,80]$. Basically, the experimental set-up contains a DC power supply, a ballast resistance, a metal anode immersed in a conductive liquid (deionized water with diluted acid) and a microplasma, acting as a cathode, and located 1-2 $\mathrm{mm}$ above the surface of the liquid (figure 3). Synthesis of nanoparticles is explained as follows. Dissolution of the anode produces metal cations that are transported to the anode where they are neutralised and agglomerate to produce nanoparticles.

\subsection{Plasma torches}

Plasma torches and micro-torches are used principally to grow nanoparticles. They can be excited by microwave power supplies (figure 4a) [81-88] or by dc generators (figure $4 \mathrm{~b}$ and 4c) [89-94]. Cathodic arc is mostly employed for powder synthesis whereas anodic arc is employed for synthesis of carbon nanostructures [92-96], with a few exceptions [97]. Indeed, anodic arc is characterized by primary anode ablation during the arc process in contrast to cathodic arc in which cathode ablation prevails. When anodic arc is implemented for carbon nanotube synthesis it is supported by ablation of the anode material and substantial part of the ablated material is deposited on the cathode.

rf excitation is commonly found in thermal plasmas [26, 98-102] to grow nanoparticles. The so-called rf induction thermal plasma (figure 4d) offers longer residence times, because of large plasma volume and low gas velocities. Furthermore, as for microwave sources, rf torches are contamination free because it can be generated without any internal electrodes.

The main issued attached to the synthesis of nanoparticles in atmospheric plasmas are the following ones: 
- Control of the purity (high quality gases, no vapour release from the walls, no leak flow, etc.)

- Control of the modal and size distributions of the particles, and consequently, the electric charges carried by these nanoparticles.

- Avoid the aggregation into clusters

- Production of core-shell and alloy nanoparticles

In regards to theory, we can also add the need to model accurately the growth of nanoparticles in thermal plasma synthesis.

The supersaturation of species in the vapour phase is the driving force for particle condensation, resulting in the production of ultrafine particles by homogeneous nucleation. In any process of powder synthesis, the plasma torch is only one part of a more complex layout in which it is associated with other devices. A quenching section improves strongly the product quality (figure $4 \mathrm{~b}$ ). By varying the quenching gas flow in this section, the width of the particle size distribution can be reduced significantly. The main difference between unquenched and quenched products is found in the tail on the large particle side of the size distribution. The size distribution of the largest part of the particles is hardly affected [103]. Next, a collector is needed to extract particles from the gas phase. Finally, process gases can be recirculated but this step usually affects the purity of the gases with process time.

Atmospheric pressure plasma torches are fed by a precursor which is mainly solid or liquid. Liquid precursors are either suspensions, aqueous or organic solutions. The precursor is admixed to the system either axially, the inner electrode playing the role of a nozzle, or outside the electrode system, perpendicularly to the plasma torch (figure 4c). The former configuration is mainly used when liquid precursors are chosen and care must taken to avoid clogging at the tip of the nozzle due to reaction products. 
These plasma torches are usually at or not too far from thermal equilibrium. Temperatures are commonly above $4000 \mathrm{~K}$ [104]. Since all the metals and most oxides are melted, there is no correlation between the size distributions of the input and the output particles. Bipolar charged particles are produced, leading to relatively broad size distribution of the output particles.

Microwave torches are characterized by gas temperatures up to a few thousands Kelvins. They are mainly excited at $2.45 \mathrm{GHz}$ by surface guided waves [81, 83-88] or by TIA-like structures [105-107] following the original idea of the Torche à Injection Axiale (TIA) proposed by Moisan et $a l$. in 1994 [108]. Sources excited by surface guided waves are useful to treat nanoparticles, confining them in the reaction tube used to guide the waves whereas TIA-like structures are more adapted to localized treatments.

\section{Isolated nanometric object}

In general, using plasmas to grow isolated nanometric objects presents the major advantage to lower the process temperature and to offer a wide range of materials that can be processed. In particular, resorting to atmospheric plasmas not only simplifies the treatment procedures but also give access to the treatment of fragile materials that could be damaged under vacuum, like living materials. For industrial applications, deposition of isolated nanometric objects could be used for direct local machining without the use of a mask [71]. With a motorized $x y z$-stage, it is possible to control the location of the deposition area on the substrate accurately and to build with these elemental units larger architectures [109]. Semiconductor with a large band-gap that could be deposited locally would present a great potential as a gassensing device [59]. The next step is to be able to grow coatings from a direct assembly of nanoparticles. Indeed, nanostructuration of composites is known to confer extraordinary properties to materials. New ultra-hard materials could be "designed" by these new processes [110]. On the other hand, the possibility to deposit isolated nanometric objects could also be 
exploited to decorate fibres for a variety of potential applications, including catalysis, sensors, electronic devices, magnetics, optics and others [111]. Finally, 1D nanostructures grown in templates such as nanotubes and nanowires, offer potential applications in nanodevices [112]. The synthesis of isolated objects at the micrometre scale by plasma at atmospheric pressure takes today three main ways. The first one is based on plasma enhanced chemical vapour deposition (PECVD) by locating the deposit on an area as small as possible. The second one focuses on the use of nanoparticles. The last one uses templates.

\subsection{Localized PECVD}

The ability to "localize" coatings by PECVD appeared in 2001. Jiang et al. [44] use the specificity of a filamentary Dielectric Barrier Discharge (260 torr - Ar-2.6 vol. $\% \mathrm{C}_{2} \mathrm{H}_{2}$ mixture) to deposit an array of carbon-based columns that grow along streamers selforganized in network. These authors mention for the first time a "localized PECVD". The plasma deposition process evolves as time passes. Three steps are clearly identified. The plasma is of the glow-type during a short period and quickly becomes filamentary, leading to dot-like structures of $10 \mu \mathrm{m}$ in diameter. Next, the localised growth of columns occurs from some of the deposited dots and it compels streamers to attach on the tips of these emerging microstructures. Thicker but fewer filaments appear progressively, attached on the highest columns. They form, after a short transient step, an unchanging pattern. The columns $(\sim 100$ $\mu \mathrm{m}$ in diameter) present naturally three different structures corresponding to each step. The transition from one mode to another is likely due to enhancement of the electric field due to shape effects. Columns are stacks of nanoparticles where carbon atoms with single, double and even triple bonds form the structure of a polymer-like network. This was show by Fourier Transformed Infra Red analyses $\left(\mathrm{C}-\mathrm{H}\right.$ at $3000-2850 \mathrm{~cm}^{-1}, \equiv \mathrm{C}-\mathrm{H}$ at $3300 \mathrm{~cm}^{-1}$ and $\mathrm{C}=\mathrm{C}$ at 1656-1600 $\mathrm{cm}^{-1}$ stretching vibration peaks and various $\mathrm{C}-\mathrm{H}$ bending vibration peaks). Oxygen is also present, due to leak flows. No information is available on the deposition 
temperature. In fact, huge gradients likely exist and distinction should be made at least between streamer-assisted deposition and deposition occurring in between streamers.

We may think that starting from a patterned surface obtained by any method prior to treatment would be a way to get columns with a high aspect ratio. However, the column width should be larger than several micrometers, the diameter of streamers being limited by the Debye's length at atmospheric pressure. Furthermore, the poor control that the user has on the stability of self-organised patterns of streamers of streamers limits drastically the use of DBD for surface patterning.

Simultaneously to the works performed by Jiang et al. [44], and without mentioning the localized nature of their coating, Babayan et al. [45] realize yet localized deposits of silica with a rf plasma jet at atmospheric pressure. However, one must wait until 2002-2003 to see the first approaches aiming to deposit isolated object. On the one hand, studies on PECVD from micro-discharges are carried out in Japan by Ito et al. [46, 47, 69, 113-115]. On the other hand, works on PECVD under vacuum using capillary are performed by Hollander et al. [109, 116, 117]. These latter authors formalize the concept of localized PECVD. A deposit is said "localized" when it might be used as building unit of 1, 2 or 3D-objects. In this sense, localized deposition differs from thin film deposition. In 2004, Kikuchi et al. [74] propose a similar reactor to that of Hollander et al. but, this time, run at atmospheric pressure.

Babayan et al. [45] designed a rf plasma jet made of two concentric electrodes separated by a $1.6 \mathrm{~mm}$ gap through which a flow of $\mathrm{He}-0.4 \% \mathrm{O}_{2}$ mixture is introduced at high rate $(49 \mathrm{slm})$. A remote plasma is thus created downstream the gap and blown out through a nozzle in the centre of which a 1.6-mm tube is used to inject the precursor (TetraEthoxyOrthoSilicate or TEOS). The film properties are strongly dependent on the surface temperature of the substrate. Hydroxyl groups detected by FTIR analyses are progressively removed as temperature rises. The deposit, which is porous and rough below $573 \mathrm{~K}$ (as observed by AFM 
measurements) becomes dense and smooth above this threshold. The growth of the film is driven by a two-step process: one involving a reaction with $\mathrm{O}$ atoms to produce silanol intermediates, followed by the decomposition of these intermediates on the film surface into $\mathrm{SiO}_{2}$. If a two-step process seems highly likely, the reaction pathways proposed by the authors must be confirmed. For instance, adsorption is said to be the rate-limiting step but desorption of $\mathrm{OH}$ is probably very slow and would need to be quantified accurately. In this situation, the decrease in the apparent deposition rate when temperature rises must be attributed to the growth of a more dense film instead of a decrease in the chemical reaction rates.

This millimetric torch treats a relatively large area, although unknown (at least twice larger). Shimizu et al. [46, 47] succeeded in building a sub-millimetric torch-assisted CVD system by creating a UHF microplasma in a quartz capillary $(500 \mu \mathrm{m}$ in diameter) where the precursor $\left(0.5 \% \mathrm{CH}_{4}\right.$ diluted in $\left.\mathrm{Ar}\right)$ is confined. A metallic wire, usually made of tungsten or molybdenum, is used as an antenna. As in the case of Babayan et al. [45], the columnar growth of cauliflower-like microstructures made of spherical graphite nuclei is described as a surface process. The crystallinity of this non-continuous film is closely related to the actual temperature of the area where crystals grow and probably to the temperature radial gradient in the plasma jet. The presence of carbon nano-onions is also noteworthy but no explanation is given on the possible origin of these objects. When a ferrocene vapour is mixed to methane and introduced in the torch, multiwall carbon nanotubes can also be grown on the metallic wire [47]. In this case, the deposition rate is relatively high (up to $120 \mu \mathrm{m} \mathrm{h}^{-1}$ ). The origin of such high deposition rates when surface reactions drive the growth of the deposit is mainly due to the hydrodynamic conditions that can drag by turbulence one of two precursors in the localized jet of the other [118].

In 2006, the same group [47, 72] used melting and evaporation of the oxidized surface of a metallic wire to deposit micrometric pillars at growth rates of $50 \mu \mathrm{m} \mathrm{s}^{-1}$. This process differs 
strongly from the previous one although it is exactly the same experimental set-up. Due to the presence of oxygen, the surface of the refractory metal is oxidized. The melting point of this oxide being much lower than that of the metal, the surface is liquid and evaporates, producing a metallic oxide vapour. At low flow rates (below $20 \mathrm{sccm}$ ), this vapour is dissociated in the plasma and species are transported downstream. At high flow rates (above $20 \mathrm{sccm}$ ), droplets are emitted mechanically from the molten surface. These droplets are nanoparticles with mean diameters of a few tens of nanometres typically. Spraying nanoparticles increases deposition rates by nearly two orders of magnitude relative to rates defined by surface reactions (from several hundreds of micrometres per hour to several tens of micrometres per second). In regards to the chemical composition of the deposit, the residence time of species changes the oxidation level of the wire surface by changing the temperature of the plasma, and then of the wire. Consequently, the shape of the nanostructures obtained under different flow rate conditions is strongly modified.

One important issue raised by these works deals with the influence that the residence time of the precursor from the end of the capillary to the substrate exerts on the characteristics of the deposit. This issue resonates with the question raised by the works of Höllander et al. [109, $116,117]$. These authors developed a process based on a similar idea, even though it was scaled to operate under low-pressure (0.2-2 mbar). A capillary, through which a precursor (HMDSO or acetylene) is fed, is located between the two electrodes of a capacitively coupled rf plasma. The lapse of time during which gaseous species are transported together, are dissociated by the plasma and do react with one another influences not only the stoichiometry of the deposit but also its morphology. At a given pressure, this parameter is affected by the plasma power, the flow rate and the distance between the capillary and the substrate (except for oxygen in carbon deposit made with acetylene where the contain is between 8 and 10 at.\% oxygen in the surface as determined by XPS). Actually, the authors found out that for shorter 
residence times of species crossing the gap from the capillary exit to the substrate, larger input power are required to dissociate gases and create precursors. The input power must be adapted to set a residence time that corresponds to the creation of the precursors. Lower as well as longer times reduce deposition rate either by incomplete conversion of gases into precursors or by creation of sufficiently large particles in the gas phase to be removed by the gas flow. This description assumes that surface reactions are responsible for the growth of the deposit. We shall see next (paragraph 3.2) that nanopowders thrown at high speed on a surface may pile up to create very similar objects. That is basically the idea proposed by Girshick, as described hereafter [119]. The previous reasoning is still valid but the time needed in the gap is now defined by the time needed to create the precursors augmented by the time needed to let the precursors form nanoparticles with a size remaining below a certain threshold. Indeed, according to results presented in reference [117], the deposition rate goes through a maximum. This threshold must now be defined and this issue will be discussed later. Another striking feature of this process concerns the unusually high deposition rates that are obtained, as in the work of Shimizu et al. [46, 47] and Mariotti et al. [40-43]. These rates reach $240 \mu \mathrm{m}$ $\mathrm{s}^{-1}$, even though the density of the deposited materials is probably much inferior to the density of the same bulk materials because of their powdery structure. The conversion efficiencies of the precursors are close to $100 \%$ at optimum input plasma power.

The concept proposed by Kikuchi et al. [74] is similar to Ito's [69] and Höllander's [109] ideas. A bevelled needle is used as rf electrode whereas the substrate is grounded. Maximum deposition rates of $1.4 \mu \mathrm{m} \mathrm{s}^{-1}$ are obtained with methane as precursor. The study of this corona-like discharge at atmospheric pressure emphasizes the link existing between the gas flow rate and the nanostructure of the deposit for a given needle diameter. The excitation temperature increases with decreasing gas flow rates because the electron temperature increases to maintain the discharge against electron loss to the wall of the needle electrode. 
Simultaneously, a maximum electron density is measured at an optimum flow velocity. At this maximum, and for high flow rates (flow velocities $>10 \mathrm{~m} \mathrm{~s}^{-1}$ ), the largest number of disc-shaped nanostructures composed of amorphous carbon and graphite is obtained. At low flow rates, the synthesis of films composed of particles, wires and CNTs is dominant. The authors could observe the single walled (SW)-CNT related Raman band corresponding to the breaching mode was observed at $260 \mathrm{~cm}^{-1}$, including D- and G-bands at 1350 and $1580 \mathrm{~cm}^{-1}$ [74]. The metallic needle and the substrate when it is metallic serve as source of catalysts for the growth of wires and CNTs. Once more, it turns out that the residence time of species plays a fundamental role in the synthesis and organization of the deposit.

In atmospheric-pressure plasmas, gas-phase collisions usually dominate over plasma-surface interactions. However, by controlling the gas flow, and the residence time of species, the relative importance of volume and surface reactions can be adjusted. That is essentially why the control of this parameter becomes so crucial in all the works previously described. All the distances must be adapted to the plasma parameters in micro-volumes. The expected consequence of this conclusion is that deposition driven by surface processes requires setting operating parameters in very narrow ranges of values. On the contrary, handling nanoparticles seems to be much easier and decreases remarkably the processing time.

The main drawback of this relative simplicity lies in the composite nature of the deposited material. As shown for instance in reference [71], the high velocity impaction of sprayed particles and their sintering induced via heat flux from the jet is probably an important factor to determine the density of the material. The particles and their interfaces constitute a kind of composite whose properties depend on the way the assembly occurs. The control of the flow at the exit of the capillary is then extremely important. This issue will be discussed in detail hereafter. 
The possibility to localize treatments with micro-plasmas was also used in other fields than deposition such as etching. In 2003, Ichiki et al. [16] perform a localized treatment at ultrahigh etching rate on silicon wafers using a microwave plasma jet of one hundred micrometers in radius. The source is excited at $100 \mathrm{MHz}$. Ichiki et al. [16] manage to etch silicon and quartz with halogens at rates approaching $70 \mu \mathrm{m} \mathrm{s}^{-1}$ and $200 \mathrm{~nm} \mathrm{~s}^{-1}$ respectively. Again, it appears that the localized nature of treatment is apt to increase the treatment rates by several orders of magnitude $[65,120]$. This increase is attributed to a comparable increase in the plasma density relative to plasma sources conventionally employed in micro-fabrication processes [121]. This ability to etch at high rates is also exploited in the field of biological materials $[13,122,123]$ but at a scale that remains macroscopic. Finally, we find that it is possible to oxidize or to clean locally metals and metallic alloys by means of localized plasmas [124].

\subsection{Nanoparticles}

According to the definition given above, localized deposition could be limited to a single nanoparticle adhering to a surface. Therefore, using nanoparticles as basic units for localized deposition makes sense.

Radio-frequency induction thermal plasmas (RF-ITP) are widely used for nanoparticle fabrication. With this kind of source, $\mathrm{TiO}_{2}$ nanoparticles $[125,126]$ and alloy particles $\left(\mathrm{Fe}^{3+}-\right.$ doped $\mathrm{TiO}_{2}$ [127] and $\left(\mathrm{Eu}^{3+}-\mathrm{Nb}^{5+}\right)$-codoped $\mathrm{TiO}_{2}$ [128]) were synthesized from liquid precursors. $\mathrm{SiO}_{2}[129,130], \mathrm{Al}_{2} \mathrm{O}_{3}[131], \mathrm{TaC}[132], \alpha$ and $\beta \mathrm{SiC}, \mathrm{WC}[133,134]$ and TiCN nanoparticles [135] were also produced. Carbon nanostructures can be grown by arc processes like SWNTs and graphene sheets [92]. The magnetic field present in this kind of process has a profound effect on the diameter, chirality, and length of the SWNTs. Synthesis of a few-layer graphene in a magnetic field presence is also possible. 
Other works $[81,82,85-87,89,90,136]$ are based on microwave plasma sources that have, according to Bang et al. [81], the following interests: they can be easily implemented and are inexpensive, they can be used for treatments in continuous processes and thus ensure a mass production. Finally, they are quite compact and easily versatile for various applications.

Several new processes have been proposed recently that exploit the specificity of high pressure plasmas.

First, the filamentary nature of Dielectric Barrier Discharges has been used to control the particle size of a unimodal distribution $[58,137]$. The interaction between a streamer and a dielectric surface creates nanoparticles with composition, size and structure that are related to plasma parameters (energy, number of streamers per unit surface and time and thermal gradients). Alloyed nanoparticles ( $\mathrm{Cu}$ core coated by a hydrocarbon shell) can be synthesised in DBDs [138]. This could also be done by post-discharge treatments since the process described in [138] is very similar to an afterglow configuration.

Second, nucleating nanoparticles in a microplasma [80] from a vapour phase offers also the possibility to synthesize alloyed nanoparticles by mixing different precursors (figure 5). In this kind of studies, the size, composition and morphology of as-grown nanoparticles is usually evaluated by high-resolution transmission electron microscopy (HRTEM) and energydispersive $x$-ray spectroscopy (EDX). The TEM results must be in agreement with the measurement of the size distribution of gas-phase nanoparticles that can be determined for example with a differential mobility analyzer coupled with a condensation particle counter.

In the case of a microplasma source, the small physical size of the plasma restricts the distribution of these nanoparticles over a small area, making possible localized synthesis and modification of materials.

Third, the use of a microplasma as "switch" in a electric circuit where a liquid phase is present constitutes a real breakthrough in nanoparticle synthesis [80]. Electrochemical 
reactions can be driven by gas-phase electrons that react at the plasma-liquid boundary with metal cations present in the solution, and they result finally in particle nucleation. The whole process is probably not straightforward but certainly assisted by energetic species from the plasma, even though the basic mechanisms governing this nucleation step are not known yet. The possibility to use a large number of liquids offers new perspectives.

It is possible to synthesise in the gas phase nanoparticles of $\mathrm{SnO}_{2}$ [89], $\mathrm{V}_{2} \mathrm{O}_{5}[85,86], \mathrm{ZnO}$ [85, 90], $\mathrm{TiN}$ [87], $\mathrm{TiO}_{2}[87,82], \mathrm{TiO}_{2-\mathrm{x}} \mathrm{N}_{\mathrm{x}}[136]$ and most of the catalysts used for the growth of carbon nanotubes $[84,139-141]$. It is also possible to obtain nanoparticles of silicon by vaporization of crystalline silicon using an atmospheric mini-arc [142]. A similar principle is used for the synthesis of cadmium oxide nanocubes [143]. Particles of noble metals (Au [144] and Pt [145]) were produced using a rf plasma [144] and an AC plasma with a liquid electrode used to easily collect the particles [145]. Polymeric nanoparticles have been produced from PTFE precursor [59], siloxane [146] and furan [147]. Finally, about carbon nanoparticles, the synthesis of spheres of graphite [148], DLC [149] fullerenes [150], sheets of graphene [151], nanodisks [91], rods [152] or crumpled paper sheets [153] is also possible. The first group to have proposed the use of nanoparticles to deposit localized structures is the group of Kashu et al. [154, 155]. The main developments based on their works were carried out at the end of the 90s [156-158]. The group of Girshick [159-163] developed the concept of depositing particles produced in a hypersonic plasma (HPPD for hypersonic plasma particle deposition). The original idea relies on the availability of mono-disperse distribution of nanoparticles by plasma and then, on the projection of these nanoparticles at high speed on a surface (figure 6a). The particle velocity is fixed by means of a pressure gradient established between the plasma source and the deposition chamber that communicate through a nozzle of controlled size. This nozzle can be heated to avoid clogging and to drive particles away from the nozzle walls by thermophoretic forces. To avoid this difficulty and to further decrease the 
size of the deposit, it is necessary to get rid of the nozzle. This can be achieved by focusing the spray of particles with aerodynamic lenses [119]. Thin plates, with an orifice located at their centre, sample successively the beam of nanoparticles. In passing through each plate, the gas contracts and then re-expands. Depending on their size, particles follow or not the gas streamlines. Large and medium particles accelerate radially towards the axis as the flow approaches the orifice. They cross the flow streamlines and, depending on their inertia, either terminate on one of them, or continue their trajectory until they hit the opposite wall. By this selection process, the lightest particles get concentrated along the axis. The particle impacts the substrate at velocity in the range $200-300 \mathrm{~m} \mathrm{~s}^{-1}$. These velocities are in the same order of magnitude as those found in the works of Shimizu et al. [46, 47] and Höllander et al. [109, $116,117]$ where supersonic velocities are reached.

The control of the flow is then extremely important to carry the nanoparticles at high speed. A free jet occurs when a high pressure gas source expands in a lower pressure background without boundary. Depending upon the ratio of upstream pressure and background pressure, the flow may reach sonic speed that is, mean velocity equal to the local speed of sound at the exit, as explained by Abhinandan and Holländer [116]. As the gas flows along the capillary length, its pressure decreases and its specific volume increases. To accommodate this increase in volume, the speed of the gas increases. The measured pressure drop along the channel length is caused by both shear and acceleration. Then, the average friction factor is a key parameter to know in order to describe the flow in the capillary but also at its exit where the pressure is atmospheric. We observe from data in table 1 that the diameter of the deposition area is nearly three times larger than the nozzle diameter. We also notice that down to $20 \mu \mathrm{m}$, the diameter of the nozzle does not change significantly the pressure drop, setting the pressure in the capillary at a sufficiently low value to avoid its explosion. However, if smaller and smaller capillary diameters are used, the upstream pressure increases. Using data given in 
[116] to calculate this friction factor, we can estimate the pressure needed to blow an argon gas through a capillary with a diameter of $100 \mathrm{~nm}$. It should be about 100 bars, a pressure requiring capillaries with large walls to avoid explosion.

We may also think that the jet expanding in the air through such a tiny orifice would diverge rapidly and the working distance between the capillary and the surface of the substrate would probably need to be set by nanopositioning.

Currently, the full width at half maximum of the thickness distribution of the deposits is at best of about several tens of micrometers (figure 7). We notice that the deposited material is made of an assembly of nanoparticles with a mean diameter of several nanometers. The deposition mechanism was carefully investigated by Hafiz et al. [110, 111, 164]. Using X-ray diffraction (XRD) with a microdiffractometer (with $100-\mu \mathrm{m}$ spatial resolution) and Auger Electron Spectrometry, deposits were found to consist of small (5-nm in diameter) singlecrystal $\beta$-SiC grains, embedded in a matrix that included both a crystalline Si phase and an amorphous $\mathrm{Si}-\mathrm{C}$ phase. These grains have approximately the same mean size as the nanoparticles exiting the aerodynamic lenses. The crystallographic phase of $\beta$-SiC grains is probably stabilized by nanoparticle impact, while the matrix is deposited by CVD.

If we consider the results presented before on the deposition of pillars by other jet-based processes, this conclusion sounds logical. Above a certain threshold, the residence time of species makes it possible to have nanoparticles, still surrounded by the vapour phase from which they nucleate. Homogeneous and heterogeneous processes can occur simultaneously, leading to a composite material, as previously discussed for localized PECVD. Therefore, the substrate temperature plays an important role on the quality of the film. We can give a rough estimate of this threshold. It depends, of course, on the kinetics of the gas phase reaction that produces nanoparticles. According to Silmy et al. [117], it is close to a fraction of millisecond. It means that for gas velocities of hundreds of meters per second, the distance 
between the nozzle exit and the substrate has to be about $1 \mathrm{~cm}$, a value which is commonly encountered.

These remarks have to be connected to some important conclusion drawn from the works performed by Pere Roca et al. $[165,166]$. Indeed, these authors made a huge effort to explain the contribution of clusters to the PECVD deposition of nanocrystalline silicon. It is, somehow, the same mechanisms that are involved in this low-pressure process. For instance, the increase of the deposition rate is also explained by the contribution of nanoparticles to the growth. The crystallinity of these nanoparticles depends on plasma composition, hydrogen atoms seeming to play the major role in the way atoms get organized in silicon clusters. Consequently, this technique could be combined with other treatments, like CVD, to tailor for instance the coating nanostructure or to design interfaces in a composite material.

To finish with this issue, we may evoke the works performed by Kakiuchi et al. [167-170] who built an atmospheric pressure plasma chemical vapour deposition system with a rotary electrode (the velocity of the electrode surface is close to $80 \mathrm{~m} / \mathrm{s}$ ). Deposition rates reach 1.6 $\mu \mathrm{m} / \mathrm{s}$ at $1000 \mathrm{~W}$ for a flow rate of helium of $1200 \mathrm{slm}$. Reactive gas molecules are carried by high speed viscous flow and homogeneously introduced into the plasma area between the electrode and the substrate by rotating the electrode. It is possible to cool the electrode surface sufficiently, so that a high power can be supplied without thermal damage of the electrode. Therefore, the deposition rate and homogeneity of the films are remarkably improved. The authors claim that particles generated in the plasma are easily removed from the plasma area along with the high-speed gas flow, we can assume that small nanoparticles are included in the film, leading to these relatively high deposition rates. But this assumption must be confirmed.

Another method proposed to get localized deposits from nanoparticles is to control their trajectory with a high voltage applied on a nano-electrode, on the principle borrowed from 
xerography [171] (figure 6b). The plasma is used only as a monodisperse source of charged nanoparticles [172]. In this case, the resolution is improved spectacularly, the deposited patterns having a characteristic dimension of about $100 \mathrm{~nm}$.

\subsection{Templates}

The growth of nano-objects can be "templated". This approach is radically different from that described in the preceding paragraph: it requires to start from nano-objects and not to synthesise them from scratch. It is possible to use nanoparticles to treat them by plasma enhanced CVD at atmospheric pressure and coat them with another material [173-177]. These treatments can take place in a fluidized bed [60, 178-181] but high pressures are needed to have a sufficiently high gas current for fluidization. The main difficulty associated with these treatments is to separate the particles from the aggregates they form under the influence of the considerable forces of inter-particle cohesion. Then, it is necessary to add additional devices, like ultrasonic transmitters [179], that provide the energy needed to disaggregate particles whose diameters are around $100 \mathrm{~nm}$ (see figure 8). This pitfall can be avoided by using a source of nanoparticles. Another important aspect of these treatments in fluidized bed is the importance of afterglow reactions as powders spend most of the time in the non-plasma area [179].

Another original approach was adopted by Li et al. $[182,183]$ who proposed in 2003 to use as templates anodized alumina (Aluminum Anodic Oxide - AAO). These templates can be described as a set of uniform and parallel nanopores of about several tens of nanometres in diameter (figure 9). Using this method, Li et al. were able to produce nanowires [183] and nanotubes [182] of carbon at low temperature $(\sim 573 \mathrm{~K})$ with a corona discharge (figure 10$)$. The CNWs synthesized by this method are mainly composed of microcrystalline graphite, full of defects. Indeed, two broad resonance peaks at 1293 and $1597 \mathrm{~cm}^{-1}$ are detected by Raman. They are assigned to the disordered carbon mode (D-band) and graphite vibration mode (G- 
band), respectively. The D-band is attributed to the defects in the curved graphene sheets, nanowire ends and finite size crystalline domains of the nanowires. The authors suggest that the growth of the nanotubes would not be driven by the Vapour-Liquid-Solid mechanism in their specific experiment. Amorphous carbon nanodots are also found on the top of the bundles of the multiwall carbon nanotubes that are buried in the alumina holes. The etching of alumina after plasma processing is then difficult and incomplete. However, this amorphous phase can be removed by an oxygen plasma [184].

The issue of the plasma penetration in the pores is interesting. The use of high pressure plasmas is particularly interesting in this case. This issue is discussed, for instance, in the treatment of woven fabrics where active species have to penetrate in micrometric pores $[185$, 186]. It gave rise to a novel process called evaporation-driven, template-assisted nanocrystal assembly (ETNA) [187, 188] whose principle is the following one. An AAO template is immersed in a dispersion containing nanocrystals. The drying of the solvent leads to a complete infiltration of the template. Next, the nanocrystals are consolidated within the template by using nanocrystal plasma polymerization and then, the template is dissolved. In the case of polymeric templates, the plasma processing consolidates the nanocrystals and removes the template at the same time. The low-pressure rf plasma treatment is performed at low power (5 W typically) and room temperature. It removes the organic capping ligands and embeds the nanocrystals in an inorganic matrix which bestows mechanical stability without interfering with the size-dependent properties of the nanocrystals. Then, this process has some similarities in its principle with the one that is to mix nanoparticles and PECVD.

On surfaces, it is convenient to use pre-deposited catalyst dots. This is particularly true for the growth of nanotubes by the Vapor-Liquid-Solid (VLS) mechanism. Prior to the introduction of the carburizing phase, catalytic nanoparticles have to be spread on the surface. This can be done using any method leading either to a chosen distribution of the dots [189-193], or to a 
random distribution, as in the case of plasma processes at atmospheric pressure [139-141, 194]. Many groups used atmospheric plasmas to grow carbon nanotubes [57, 61, 66, 67, 83, $88,98,105,195-206]$. A detailed review on the subject is available [200].

Plasma processes at atmospheric pressure would be more interesting than processes under vacuum because they would produce more easily single-walled nanotubes (SWCNT). The reason foreseen by Hinkov [195] in 2005 and corroborated by the results obtained by Nozaki et al. [200, 207], is that atmospheric plasmas prevent damages induced by energetic ions on the nanotubes during growth. Sheaths are very collisional at atmospheric pressure, leading to ion energy distributions shifted towards low energies. Another argument is that at high pressure, the energy of the neutral atoms is low too, because of their short mean free path. Otherwise, it would be possible to use post-discharge under vacuum to obtain comparable results. According to these authors, the growth of carbon SWCNT would be controlled by low-energy ions like $\mathrm{CH}_{4}^{+}$or $\mathrm{CH}_{3}^{+}$.

Finally, silicon nanocones, CNTs and other nanostructures can be synthesised on Fe-coated Si substrates by a rf-plasma microplasma assisted process combining etching (or sputtering or evaporation) and catalytic growth [208]. As often with this kind of sources, results are very sensitive to the distance between the substrate and the microplasma jet. One nice conclusion of this work is that growth mechanisms, even if they are still unclear, can be selected to get nanostructures of very different shapes with one process.

\section{Self-organized nanostructures}

Nanotechnology aims at achieving a highly controllable and predictable level in the synthesis of nanostructures and their assemblies. On the other hand, nanoparticles have attracted wide attention due to their unique size-dependent properties including superparamagnetism, chemilumiescence and catalysis. To fully harness the potential capabilities of nanoparticles, we need to develop new methods to assemble them into useful patterns or structures. These 
self-assembled structures promise new opportunities for developing miniaturized optical, electronic, optoelectronic, and magnetic devices.

More specifically, oxides have attracted much attention [40-43, 70-72] due to some of their properties like electrochromic, photochromic, optical, and field emission properties that could be exploited in applications including, e.g., chemical synthesis, petroleum refining, sensors, optical/optoelectronic devices, catalysis, smart windows, display, supercapacitor and battery applications.

Electric field-induced nanostructuring effects, such as organization into an array of nanoparticles, formation of nanowires and transition from amorphous to nanocrystalline states, has been demonstrated for thin film surfaces [209]. We shall see that some of these effects are also observed with plasma assisted processes. In a second time, we shall show that dispersion forces can be used, leading to dewetting. Physical assembly driven by mechanical force of stress will be presented next. When buckling takes place, it relieves the stress generated by the difference in the thermal expansion coefficients of the deposit and the substrate.

\subsection{Building with electric fields}

Self-organization of nanostructures by plasma processes at atmospheric pressure was first observed during the deposition of metallic oxides [40]. The use of oxides stems from their semi-conductor property which induces diffusion mechanisms driven by charge carriers. Consequently, these diffusion mechanisms can be oriented by electric fields [210]. This effect is applied successfully to increase the oxidation rate of metals [210]. Here, the electric field must be parallel to the surface to promote surface rather than volume diffusion.

This approach has been implemented by Mariotti et al. [40-43, 211, 212] using a capillary process derived from the principle presented in references [46, 47, 70-72]. The high voltage is 
applied directly onto a metallic wire which serves as a source of metal filler rather than being applied to a coil wound around the capillary where the wire is.

These authors have proposed to take advantage of using oxides in the following manner. An oxygen-containing plasma, created by a very high-frequency power supply, is used to produce nanoparticles from the metallic wire [46, 47, 70-72]. The filament is oxidized and emits vapours or droplets depending on the total flow rate. Indeed, oxides have evaporation temperatures far below the temperature of the metal constituting the wire, especially if it is refractory like tungsten or molybdenum, and lie in the range of the plasma temperatures. In the specific case of molybdenum, two oxides must be considered: $\mathrm{MoO}_{2}$ with a melting temperature of $1373 \mathrm{~K}$ and $\mathrm{MoO}_{3}$ with a melting temperature of $1068 \mathrm{~K}$. If the plasma temperature lies between these two melting temperatures, $\mathrm{MoO}_{2}$ evaporates and $\mathrm{MoO}_{3}$ melts. Then, droplets are ejected in the gas phase and undergo a spheroidization process during the solidification step that leads to the synthesis of nanospheres. This step may be interrupted by shortening the plasma-to-sample distance, what produces irregular shapes. The consumption of the wire changes the coupling of the applied voltage and it increases the distance between wire and substrate $[41,43]$. The wire temperature decreases, and so the gas temperature, leading to a highly non-equilibrium state. Then, the growth of $\mathrm{MoO}_{3}$ on the surface of the substrate is completely controlled by kinetic processes. This gives rise to the formation of nanosheets of $\mathrm{MoO}_{3}$.

It is possible by using atmospheric plasma to orientate the growth and morphology of nanostructures on surfaces. If the versatility of this type of processes is a major asset, it is not shown nor ruled out that the plasma plays a real role on the synthesis of nanostructures. Indeed, we might think that a process based on thermal evaporation only could lead to similar results. 
However, this afterglow-like device turns out to be of no use to organize nanostructures into functional architectures. This problem was solved by applying the VHF field directly on a copper electrode supporting the substrate $[40-43,211,212]$. In this configuration, it is possible to expose the surface to a high flux of charged particles from the plasma and also to create a very specific distribution of electric field where the field lines leave the surface of the substrate and converge at the wire tip [40]. This phenomenon is not specific to oxides deposition since it was also observed with carbon deposition made to grow directional connections between silicon nanocrystals or silver nanoparticles randomly distributed on a surface (figure 11) [40]. Modelling studies reveal that the directional growth of connections between dots $[211,212]$ is controlled by surface diffusion of adatoms which is influenced by the distribution of the local electric field around the dots. Thus, it appears that the presence of a particle on the surface can exacerbate the local electric field and change the isotropy of growth. It would be interesting to control independently the plasma and the electric field distribution on the surface, the process used in references [40-43, 211, 212] coupling these two parameters.

Self-organization of micro-filaments may be used as demonstrated by Jiang et al. [44]. As described previously, a network of immobile streamers could be progressively created in a DBD by tip effect on growing microstructures. These microstructures were separated one from each other by $3 \mathrm{~mm}$. They consist of particles of one hundred nanometers in diameter. It seems likely that the charged powders formed in the gas phase are stacked on the columns where the electric field is locally exacerbated. However, self-organization of filaments is not so easy to control [213], and it is certainly much easier to use arrays of microplasmas [214216] to grow patterned objects on surfaces.

\subsection{Using high temperatures and stress to control surface energies}


For the synthesis of carbon nanotubes according to the VLS mechanism, it is possible to start from catalyst droplets spread over the surface of the substrate used for growth. The formation of such droplets is commonly provided by dewetting of a nanometric layer of the catalyst deposited by various methods. This mechanism ensures naturally the formation of catalytic nanoparticles $[217,218]$. This process is studied more fundamentally in the case, for example, of the dewetting of native silica on SOI (silicon-on-insulator) [219, 220]. The important condition to fulfil in this case is to control the "purity" of the interface between the film and the surface. Any contaminant affects strongly the dewetting process and the way particles get distributed over the surface.

G. Arnoult et al. [221, 222] have proposed to use a microwave micro-post-discharge at atmospheric pressure to create nanostructures - nanodots and nanocells (figure 12) - of thermally insulating materials (silica) on thermally conductive substrates. These authors resort to localized CVD from hexamethyldisiloxane injected in $\mathrm{Ar}-\mathrm{O}_{2}$ post-discharges of about 500 micrometers in diameter. In this process, the combined role of the high temperatures used (the afterglow reaches nearly $1800 \mathrm{~K}$ ) which define the interfacial energy between substrate and deposit and stress resulting from high thermal gradients is used to promote an isotropic buckling of the deposited film, leading to nanostructure surfaces.

The use of stress [223] and the control of the interface free energy [224] drive selforganisation processes. In the first case, cracks are formed with regular patterns in a thin film by stress relaxation during annealing treatment. In the second case, self-assembly results from minimization of the interface free energy.

This type of approaches raises questions about the role of the plasma in the formation of these nanostructures. For example, the formation of iron oxide nano-rods can be achieved by rf plasma [225] or by simple thermal oxidation [226]. Obviously, the plasma way offers greater versatility, especially because it allows the production of such nano-rods at low temperature. 
Moreover, in this example, it is also possible to grow nano-belts by adjusting the growth temperature [227, 228]. But there are conditions of thermal oxidation, which also give the possibility to select the morphology of nano-oxides in a wide range of possible shapes [229, 230]. Having a directional flux of ions towards the surface in the case of low pressure plasmas offers increased versatility to the process. From then on, it is nevertheless difficult to conclude that this specificity can be extended to plasmas at atmospheric pressure.

\section{Conclusion}

Atmospheric plasmas have a simple implementation that makes them attractive as a source in the production processes of nano-objects. The current methodologies are mainly based on those established in low-pressure processes. The specificities of plasmas at high pressure, as their small size, their self-organization or their filamentation have been little or not exploited in the development of nanomaterials.

In this work, several important results could be emphasised:

- Self-organisation of streamers in high pressure plasmas is likely a difficult way to follow to grow nanstructures on surface.

- Glow discharges at atmospheric pressure offer "smooth" conditions that are suitable for controlled deposition of nanostructures over large area.

- Plasma jets are versatile tools but their performance and the reproducibility of the results is strongly dependant on the hydrodynamic distribution of the precursors, on the way the electric fields are applied and on the control of the positioning of the plasma in regards to the substrate.

- The spatial resolution of localized PECVD is not currently sufficient to build micro-electromechanical-systems (MEMS) and micro-total-analytical-system (A-TAS), composed of elements such as electrode, circuit, and channel smaller than $100 \mu \mathrm{m}$ in diameter or width. 
Furthermore, deposition of low melting-point materials such as polyethylene terephthalate (PET), often used as base material for A-TAS, must be developed.

- Plasma enhanced chemical vapour deposition (PECVD) process combined with nanoparticle beams are promising hybrid processes. They offer high deposition rates, possible control of interfaces composition and accurate localisation of the deposition area.

- Plasmas in or on liquids show remarkable potentialities and if they are extremely simple to use, their understanding is by far much more complex.

- Using templates to grow isolated objects is very well adapted to atmospheric pressure plasmas.

- Self-organisation is possible with atmospheric pressure plasmas but only a few numbers of routes have been tested and much has still do be done to build controlled architectures. 


\section{Bibliography}

[1] Kogelschatz U 2003 Plasma Chem. Plasma Proc. 231

[2] Schütze A, Jeong J Y, Babayan S E, Park J, Selwyn G S and Hicks R F 1998 IEEE Trans. Plasma Sci. 261685

[3] Massines F, Rabehi A, Decomps F, Ben Gadri R, Ségur P and Mayoux C 1998 J. Appl. Phys. 832950

[4] Kanazawa S, Kogoma M, Moriwaki T and Okazaki S 1988 J. Phys. D: Appl. Phys. 21838

[5] Golubovskii Yu B, Maiorov V A, Behnke J and Behnke J F 2003 J. Phys. D: Appl. Phys. 3639

[6] Tachibana K 2006 IEEJ Trans. Elec. Electron. Eng. 1145

[7] Wang Q, Economou D J and Donnelly V M 2006 J. Appl. Phys. 100023301

[8] Foest R, Schmidt M and Becker K 2006 Int. J. Mass Spectrom. 24887

[9] Makasheva K, Muñoz Serrano E, Hagelaar G, Boeuf J-P and Pitchford L C 2007 Plasma Phys. Control. Fusion 49 B233

[10] Aubert X, Bauville G, Guillon J, Lacour B, Puech V and Rousseau A 2007 Plasma Sources Sci. Technol. 1623

[11] Stoffels E, Flikweert A J, Stoffels W W and Kroesen G M W 2002 Plasma Sources Sci. Technol. 11383

[12] Laroussi M 2005 Plasma Process. Polym. 2391

[13] Fridman G Friedman G Gutsol A Shekhter A B Vasilets V N and Fridman A 2008 Plasma Process. Polym. 5503

[14] Boudam M K Moisan M Saoudi B Popovici C Gherardi N and Massines F 2006 J. Phys. D: Appl. Phys. 393494

[15] Iza F Kim G J Lee S M Lee J K Walsh J L Zhang Y T and Kong M G 2008 Plasma Process. Polym. 5322 
[16] Ichiki T, Sugiyama Y, Taura R, Koidesawa T and Horiike Y 2003 Thin Solid Films 435 62

[17] Cardoso R P, Belmonte T, Noël C, Kosior F and Henrion G 2009 J. Appl. Phys. 105 093306

[18] Brauer I, Punset C, Purwins H-G, and Boeuf J-P 1999 J. Appl. Phys. 857569

[19] Ráhel' J and Sherman D M 2005 J. Phys. D: Appl. Phys. 38547

[20] Maximov A V and Schlüter H 1999 Phys. Scr. 60556

[21] Meyyappan M, Delzeit L, Cassell A and Hash D 2003 Plasma Sources Sci. Technol. 12 205

[22] Melechko A V, Merkulov V I, McKnight T E, Guillorn M A, Klein K L, Lowndes D H and Simpson M L 2005 J. Appl. Phys. 97041301

[23] Ostrikov K 2005 Rev. Mod. Phys. 77489

[24] Gordillo-Vazquez F J, Herrero V J and Tanarro I 2007 Chem.Vap. Depos. 13267

[25] Ostrikov K 2007 IEEE Trans. Plasma Sci. 35127

[26] Ostrikov K and Murphy A B 2007 J. Phys. D: Appl. Phys. 402223

[27] Ostrikov K 2009 Vacuum 834

[28] Kortshagen U 2009 J. Phys. D: Appl. Phys. 42113001

[29] Meyyappan M 2009 J. Phys. D: Appl. Phys. 42213001

[30] Mariotti D and Sankaran R M 2010 J. Phys. D: Appl. Phys. 43323001

[31] Ostrikov K, Levchenko I, Cvelbar U, Sunkara M K and Mozetic M 2010 Nanoscale 2 2012

[32] Zheng J, Yang R, Xie L, Qu J, Liu Y and Li X 2010 Advanced Materials 221451

[33] Ostrikov $\mathrm{K}$ and $\mathrm{Xu} \mathrm{S}$ "Plasma-Aided Nanofabrication: From Plasma Sources to Nanoassembly” 2007 Wiley-VCH Verlag GmbH and Co. KGaA, Weinheim. 
[34] Ostrikov K "Plasma Nanoscience: Basic Concepts And Applications Of Deterministic Nanofabrication” 2008 Wiley-VCH Verlag GmbH and Co. KGaA, Weinheim.

[35] Mariotti D and Mohan Sankaran R 2011 J. Phys. D: Appl. Phys. 44174023

[36] Ostrikov K, Long J D, Rutkevych P P and Xu S 2006 Vacuum 801126

[37] Ho J C, Levchenko I and Ostrikov K 2007 J. Appl. Phys. 101094309

[38] Wang F L, Jiang J C and Meletis E I 2003 Appl. Phys. Lett. 832423

[39] Mitani S, Teraji T and Ito T 2006 Diamond Relat. Mater. 151544

[40] Mariotti D, Švrček V and Kim D-G 2007 Appl. Phys. Lett. 9118311

[41] Mariotti D, Lindström H, Chandra Bose A and Ostrikov K 2008 Nanotechnol. 19495302

[42] Mariotti D, Chandra Bose A and Ostrikov K 2009 IEEE Trans. Plasma Sci. 371027

[43] Mariotti D and Ostrikov K 2009 J. Phys. D: Appl. Phys. 42092002

[44] Jiang N, Fa Qian S, Wang L and Xian Zhang H 2001 Thin Solid Films 390119

[45] Babayan S E, Jeong J Y, Schütze A, Tu V J, Moravej M, Selwyn G S and Hicks R F 2001 Plasma Sources Sci. Technol. 10573

[46] Shimizu Y, Sasaki T, Ito T, Terashima K and Koshizaki N 2003 J. Phys. D: Appl. Phys. 362940

[47] Shimizu Y, Sasaki T, Liang C, Bose A C, Ito T, Terashima K and Koshizaki N 2005 Chem. Vap. Depos. 11244

[48] Staacks D, Gutsol A F, Friedman G and Fridman A 2008 NATO 2008 NATO Science for Peace and Security Series A: Chemistry and Biology Plasma assisted decontamination of biological and chemical agents, Ed. by Selçuk Gūçeri and Alexander Fridman, Springer 79

[49] Staack D, Fridman A, Gutsol A, Gogotsi Y and Friedman G 2008 Angewandte Chemie International Edition $\mathbf{4 7} 8020$

[50] Chirokov A, Gutsol A and Fridman A 2005 Pure Appl. Chem. 77487 
[51] Massines F, Ségur P, Gherardi N, Khamphan C and Ricard A 2003 Surf. Coat. Technol., 174-175 8

[52] Foest R, Schmidt M and Becker K 2006 Int. J. Mass Spectrom. 24887

[53] Laroussi M and Akan T 2007 Plasma Proc. Polym. 4777

[54] Gomez E, Amutha Rani D, Cheeseman C R, Deegan D, Wise M and Boccaccini A R 2009 J. Hazardous Mat. 161614

[55] Tendero C, Tixier C, Tristant P, Desmaison J and Leprince P 2006 Spectrochim. Acta Part B: Atom. Spectrosc., 612

[56] Fridman A, Chirokov A and Gutsol A 2005 J. Phys. D: Appl. Phys. 38 R1

[57] Nozaki T, Kimura Y and Okazaki K 2002 J. Phys. D: Appl. Phys. 352779

[58] Jidenko N, Jimenez C, Massines F and Borra J-P 2007 J. Phys. D: Appl. Phys. 404155

[59] Guo Y, Zhang J, Xu J and Yu J 2008 Appl. Surf. Sci 2543408

[60] Tanaka K, Kogoma M and Ogawa Y 2006 Thin Solid Films 506-507 159

[61] Lee Y-H, Kyung S-J, Kim C-W and Yeom G-Y 2006 Carbon 44 L799

[62] Lee Y-H, Kyung S-J, Jeong C-H and Yeom G-Y (2005) Jpn. J. Appl. Phys., 44 L78

[64] Park J B, Oh J S, Gil E, Kyoung S-J, Kim J-S and Yeom G-Y 2009 J. Phys. D: Appl. Phys. 42215201

[65] Park J B, Kyung S J and Yeom G Y 2008 J. Appl. Phys. 104083302

[66] Kyung S-J, Lee Y-H Kim C-W, Lee J-H and Yeom G-Y 2006 Thin Solid Films 506-507 268

[66] Kyung S-J, Park J-B, Voronko M, Lee J-H and Yeom G-Y 2007 Carbon 45649

[67] Jiang N, Chen H-Y and Qian S-F 2005 Chin. Phys. Lett. 22161

[68] Staack D Farouk B Gutsol A and Fridman A 2005 Plasma Sources Sci. Technol. 14700

[69] Ito T and Terashima K 2002 Appl. Phys. Lett. 802648 
[70] Shimizu Y, Chandra Bose A, Mariotti D, Sasaki T, Kirihara K, Suzuki T, Terashima K and Koshizaki N 2006 Jpn. J. Appl. Phys. 458228

[71] Shimizu Y, Sasaki T, Chandra Bose A, Terashima K and Koshizaki N 2006 Surf. Coat. Technol. 2004251

[72] Chandra Bose A, Shimizu Y, Mariotti D, Sasaki T, Terashima K and Koshizaki N 2006 Nanotechnol. 175976

[73] Mariotti D, Shimizu Y, Sasaki T and Koshizaki N 2007 J. Appl. Phys. 101013307

[74] Kikuchi T, Hasegawa Y and Shirai H 2004 J. Phys. D: Appl. Phys. 371537

[75] Narendra J J, Grotjohn T A and Asmussen J 2008 Plasma Sources Sci. Technol. 17 035027

[76] Kim J, Katsurai M, Kim D and Ohsaki H 2008 Appl. Phys. Lett. 93191505

[77] Iza F and Hopwood J 2005 Plasma Sources Sci. Technol. 14397

[78] Hopwood J, Iza F, Coy S and Fenner D B 2005 J. Phys. D: Appl. Phys. 381698

[79] Hopwood J and Iza F 2004 J. Anal. At. Spectrom. 191145

[80] Chiang W-H, Richmonds C and Sankaran R M 2010 Plasma Sources Sci. Technol. 19 034011

[81] Uk Bang C, Cheol Hong Y and Sup Uhm H 2007 Surf. Coat. Technol. 2015007

[82] Hong Y C, Bang C U, Shin D H and Uhm H S 2005 Chem. Phys. Lett. 413454

[83] Chen C-K, Lee Perry W, Xu H, Jiang Y and Phillips J 2003 Carbon 412555

[84] Cheol Hong Y and Uhm H S 2005 Phys. Plasma 1253504

[85] Hun Kim J, Cheol Hong Y and Sup Uhm H 2007 Surf. Coat. Technol. 2015114

[86] Shin D H, Uk Bang C, Cheol Hong Y and Sup Uhm H 2006 Mat. Chem. Phys. 99269

[87] Uhm H S, Hong Y C and Shin D H 2006 Plasma Sources Sci. Technol. 15 S26

[88] Smiljanic O, Stansfield B L, Dodelet J-P, Serventi A and Desilets S 2002 Chem. Phys. Lett. 356189 
[89] Im J-H, Lee J-H and Park D-W 2008 Surf. Coat. Technol. 2025471

[90] Liao S-C, Lin H-F and Hong S-W 2005 "Nanostructured zinc oxide photocatalyst for visible light and manufacturing method of the same" US Patent 0249660

[91] Meguro T, Tsuji N, Saito S, Yamamoto Y, Mise T and Watanabe K 2008 Surf. Coat. Technol. 2025356

[92] Keidar M, Shashurin A, Volotskova O, Raitses Y and Beilis I I 2010 Phys. Plasmas 17 057101

[93] Keidar M, Levchenko I, Arbel T, Alexander M, Waas A M and Ostrikov K 2008 Appl. Phys. Lett. 92043129

[94] Keidar M, Levchenko I, Arbel T, Alexander M, Waas A M and Ostrikov K 2008 J. Appl. Phys. 103094318

[95] Keidar M, Raitses Y, Knapp A and Waas A M 2006 Carbon 441022

[96] Keidar M and Beilis I I 2009 J. Appl. Phys. 106103304

[97] Takikawa H, Yatsuki M, Sakakibara T and Itoh S 2000 J. Phys. D: Appl. Phys. 33826

[98] Cota-Sanchez G, Soucy G, Huczko A and Lange H 2005 Carbon 433153

[99] Yoshida T, Kawasaki A, Nakagawa K and Akashi K 1979 J. Mater. Sci. 141624

[100] Yoshida T and Akashi K 1981 Trans. Japan Inst. Met. 22371

[101] Kogelschatz U 2004 Plasma Phys. Control. Fusion 46 B63

[102] Cabral V and Silva R 2010 "Nanomaterials: Properties, Preparation and Processes" (New York: Nova Science Publishers)

[103] Goortani B M, Mendoza N and Proulx N 2006 Int. J. Chem. React. Eng. 4 A33

[104] Vollath D 2008 J. Nanopart. Res. 1039

[105] Jašek O, Eliáš M, Zajíčková L, Kudrle V, Bublan M, Matějková J, Rek A, Buršík J and Kadlečíková M 2006 Mater. Sci. Eng. C 261189

[106] Wu L, Ma Z, He A and Wang J 2010 J. Hazardous Mat. 173305 
[107] Wilson J I B, Scheerbaum N, Karim S, Polwart N, John P, Fan Y and Fitzgerald A G (2002) Diamond Relat. Mat. 11918

[108] Moisan M, Sauvé G, Zakrzewski J and Hubert J 1994 Plasma Sources Sci. Technol. 3584

[109] Holländer A and Abhinandan L 2003 Surf. Coat. Technol. 174-175 1175

[110] Hafiz J, Mukherjee R, Wang X, Heberlein J V R, McMurry P H, Girshick S L 2006 Thin Solid Films 5151147

[111] Hafiz J, Wang X, Mukherjee R, Mook W, Perrey C R, Deneen J, Heberlein J V R, McMurry P H, Gerberich W W, Carter C B and Girshick S L 2004 Surf. Coat. Technol. 188-189 364

[112] Xia Y, Yang P, Sun Y, Wu Y, Mayers B, Gates B, Yin Y, Kim F and Yan H 2003 Adv. Mater. 15353

[113] Ito T, Izaki T and Terashima K 2001 Thin Solid Films 386300

[114] Ito T, Izaki T and Terashima K 2000 Surf. Coat. Technol. 133-134 497

[115] Ito T and Terashima K 2001 Thin Solid Films 390234

[116] Abhinandan L and Holländer A 2004 Thin Solid Films 457241

[117] Silmy K, Holländer A, Dillmann A and Thömel J 2005 Surf. Coat. Technol. 200368

[118] Cardoso R P, Belmonte T, Henrion G, Gries T and Tixhon E 2010 J. Appl. Phys. 107 024909

[119] Girshick S L 2008 J. Nanopart. Res. 10935

[120] Okumura T, Saitoh M, Yashiro Y and Kimura T 2003 Jpn. J. Appl. Phys. 423995

[121] Ichiki T, Taura R, Horiike Y 2004 J. Appl. Phys. 9535

[122] Mericam-Bourdet N, Laroussi M, Begum A and Karakas E 2009 J. Phys. D: Appl. Phys. 42055207 
[123] van der Laan E P, Stoffels E and Steinbuch M 2006 Plasma Sources Sci. Technol. 15 582

[124] Kim M C, Yang S H, Boo J-H and Han J G 2003 Surf. Coat. Technol. 174-175 839

[125] Li J G, Kamiyama H, Wang X H, Moriyoshi Y and Ishigaki T 2006 J. Eur. Ceram. Soc. 26423

[126] Li J G, Wang X H, Kamiyama H, Ishigaki T and Sekiguchi T 2006 Thin Solid Films 506-507 292

[127] Wang X H, Li J-G, Kamiyama H, Katada M, Ohashi N, Moriyoshi Y and Ishigaki T 2005 J. Am. Chem. Soc. 12710982

[128] Zhang C, Li J, Leng Y, Uchikoshi T, Watanabe T and Ishigaki T 2010 Thin Solid Films $5183531-4$

[129] Goortani B M, Proulx P, Xue S and Mendoza-Gonzalez N Y 2007 Powder Technol. 175 22

[130] Szépvölgyi J, Mohai I, Károly Z and Gál L 2008 J. Eur. Ceram. Soc. 28895

[131] Shin J W, Miyazoe H, Leparoux M, Siegmann S, Dorier J L and Hollenstein C 2006 Plasma Sources Sci. Technol. 15441

[132] Ishigaki T, Oh S M, Li J G and Park D W 2005 Sci. Technol. Adv. Mater. 6111

[133] Leparoux M, Schreuders C, Shin J W and Siegman S 2005 Adv. Eng. Mater. 7349

[134] Leconte Y, Leparoux M, Portier X and Herlin-Boime N 2008 Plasma Chem. Plasma Process. 28233

[135] Leparoux M, Kihn Y, Paris S and Schreuders C 2008 Int. J. Refract. Met. Hard Mater. 26277

[136] Bai H, Chen C, Lin C, Den W and Chang C 2004 Ind. Eng. Chem. Res. 437200

[137] Borra J P, Jidenko N and Bourgeois E 2009 Eur. Phys. J. Appl. Phys. 4722804

[138] Lei H, Tang Y, Li J, Luo J and Li X 2006 Appl. Phys. Lett. 88083111 
[139] Chiang W-H and Mohan Sankaran R 2007 Appl. Phys. Lett. 91121503

[140] Chiang W-H and Mohan Sankaran R 2008 J. Phys. Chem. C 11217920

[141] Chiang W-H and Mohan Sankaran R 2008 Adv. Mater. 204857

[142] Liu M, Lu G and Chen J 2008 Nanotechnol. 19265705

[143] Kim J H, Hong Y C and Uhm H S 2007 Jap. J. Appl. Phys. 464351

[144] Demoisson F, Raes M, Terryn H, Guillot J, Migeon H-N and Reniers F 2008 Surf. Interface Anal. 40566

[145] Shim J, Joung K Y, Ahn J H and Lee W M 2007 J. Electrochem. Soc. 154 B165

[146] Rahman M, Amsarani R, Mooney D A, MacElroy J M D and Dowling D P $2009 \mathrm{~J}$. Nanosci. Nanotechnol. 93506

[147] Gok A and Oksuz L 2007 J. Macromol. Sci. A: Pure Appl. Chem. 441095

[148] Zou Q and Wang M Z 2009 Micro Nano Lett. 463

[149] Bian X, Chen Q, Zhang Y, Sang L and Tang W 2008 Surf. Coat. Technol. 2025383

[150] Terajima T, Chaudhary K A, Inomata K and Koinuma H 2003 J. Nanosci. Nanotechnol. 13231

[151] Dato A, Radmilovic V, Zonghoon Lee, Phillips J and Frenklach M 2008 Nano Lett. 8 2012

[152] Zou Q, Wang M Z, Li Y G and Zou L H 2009 J. Low. Temp. Phys. 157557

[153] Moreno-Couranjou M, Monthioux M, Gonzalez-Aguilar J and Fulcheri L 2009 Carbon 472310

[154] Kashu S, Fuchita E, Manabe T and Hayashi C 1984 Jpn. J. Appl. Phys. 23 L910

[155] Oda M, Katsu I, Tsuneizumi M, Fuchita E, Kashu S and Hayashi C 1993 Mater. Res. Soc. Symp. Proc. 286121.

[156] Schroth A, Maeda R, Akedo J and Ichiki M 1998 Jpn. J. Appl. Phys. 375342

[157] Akedo J and Lebedev M 1999 Jpn. J. Appl. Phys. 385397 
[158] Akedo J, Ichiki M, Kikuchi K and Maeda R 1998 Sens. Actuators A 69106

[159] Rao N P, Lee H J, Kelkar M, Hansen D J, Heberlein J V R, McMurry P H and Girshick S L 1997 Nanostruct. Mater. 9129

[160] Rao N P, Tymiak N, Blum J, Neuman A, Lee H J, Girshick S L, McMurry P H and Heberlein J 1998 J. Aerosol. Sci. 29707

[161] Rao N P, Girshick S L, McMurry P H and Heberlein J V R 1999 "Production of nanostructured materials by hypersonic plasma particle deposition" US Patent 5874134

[162] Rao N P, Heberlein J V R, Gerberich W W, Girshick S L and McMurry P H 2005 "Apparatus and method for synthesizing films and coatings by focused particle beam deposition" US patent 6924004

[163] Blum J, Tymiak N, Neuman A, Wong Z, Rao N P, Girshick S L, Gerberich W W, McMurry P H and Heberlein J V R 1999 J. Nanopart. Res. 131

[164] Hafiz J, Mukherjee R, Wang X, McMurry P H, Heberlein J V R and Girshick S L 2006 J. Thermal Spray Technol. 15822

[165] Roca i Cabarrocas P, Fontcuberta i Morral A, Lebib S and Poissant Y 2002 Pure Appl. Chem. 74359

[166] Chaabane N, Suendo V, Vach H and Roca i Cabarrocas P 2006 Appl. Phys. Lett. 88 203111

[167] Kakiuchi H, Nakahama Y, Ohmi H, Yasutake K, Yoshii K and Mori Y 2005 Thin Solid Films 47917

[168] Mori Y, Yoshii K, Kakiuchi H and Yasutake K 2000 Rev. Sci. Instrum. 713173

[169] Mori Y, Yoshii K, Yasutake K, Kakiuchi H, Ohmi H and Wada K 2003 Thin Solid Films 444138

[170] Mori Y, Kakiuchi H, Yoshii K, Yasutake K and Ohmi H 2003 J. Phys. D: Appl. Phys. 363057 
[171] Barry C R, Lwin N Z, Zheng W and Jacobs H O 2003 Appl. Phys. Lett. 835527

[172] Cole J J, Lin E-C, Barry C R and Jacobs H O 2009 Appl. Phys. Lett. 95113101

[173] Vons V, Creyghton Y and Schmidt-Ott A 2006 J. Nanopart. Res. 8721

[174] Marino E, Huijser T, Creyghton Y, van der Heijden A 2007 Surf. Coat. Technol. 201 9205

[175] He W, Guo Z, Pu Y, Yan L and Si W 2004 Appl. Phys. Lett. 85896

[176] Szabová R, Černáková L, Wolfová M and Černák M 2009 Acta Chimica Slovaca 270

[177] Nessim C, Boulos M and Kogelschatz U 2009 Eur. Phys. J. Appl. Phys. 4722819

[178] Mori T, Tanaka K, Inomata T, Takeda A and Kogoma M 1998 Thin Solid Films 31689

[179] Nakajima T, Tanaka K, Inomata T and Kogoma M 2001 Thin Solid Films 386208

[180] Ogawa S, Takeda A, Oguchi M, Tanaka K, Inomata T and Kogoma M 2001 Thin Solid Films 386213

[181] Jung S H, Park S M, Park S H and Kim S D 2004 Ind. End. Chem. Res. 435483

[182] Li M-X, Hu Z, Wang X-Z, Wu Q and Chen Y 2003 Thin Solid Films 435116

[183] Li M-X, Hu Z, Wang X-Z, Wu Q, Chen Y and Tian Y-L 2004 Diamond Relat. Mater. 13111

[184] Jeong S-H, Hwang H-Y, Hwang S-K and Lee K-H 2004 Carbon 422073

[185] Wang C X, Ren Y and Qiu Y P 2007 Surf. Coat. Technol. 20277

[186] Wang C X, Liu Y, Xu H L, Ren Y and Qiu Y P 2008 Appl. Surf. Sci. 2542499

[187] Ghadimi A, Cademartiri L, Kamp U and Ozin G A 2007 Nano Letters 73864

[188] Cademartiri L, von Freymann G, Arsenault A C, Bertolotti J, Wiersma D S, Kitaev V and Ozin G A 2005 Small 11184

[189] Teo K B K, Chhowalla M, Amaratunga G A J, Milne W I, Hasko D G, Pirio G, Legagneux P, Wyczisk F and Pribat D 2001 Appl. Phys. Lett. 791534 
[190] Fan S, Chapline M G, Franklin N R, Tombler T W, Cassell A M and Dai H 1999 Science 283512

[191] Wei B Q, Vajtai R, Jung Y, Ward J, Zhang R, Ramanath G and Ajayan P M 2002 Nature 416495

[192] Merkulov V I, Lowndes D H, Wei Y Y, Eres G and Voelkl E 2000 Appl. Phys. Lett. 76 3555

[193] Sohn J I, Lee S, Song Y-H, Choi S-Y, Cho K-I and Nam K-S 2001 Appl. Phys. Lett. 78 901

[194] Barankin M Creyghton Y and Schmidt-Ott A 2006 J. Nanoparticle Res. 8511

[195] Hinkov I, Farhat S and Scott C D 2005 Carbon 432453

[196] Jašek O, Eliáš M, Zajíčková L, Kučerová Z, Matějková J, Rek A and Buršík J 2007 J. Phys. Chem. Solids 68738

[197] Kyung S-J, Lee Y-H, Kim C-W, Lee J-H and Yeom G-Y 2006 Carbon 441530

[198] Kyung S-J, Voronko M, Lee Y-H, Kim C-W, Lee J-H and Yeom G-Y 2007 Surf. Coat. Technol. 2015378

[199] Lee Y-H, Jang H-S, Eom G-Y, Lee B-J, Burk D, Overzet L and Lee G S 2008 Mater. Lett. 623849

[200] Nozaki T and Okazaki K 2008 Plasma Proc. Polym. 5300

[201] Yoshiki H, Okada T, Hirai K and Hatakeyama R 2006 Jap. J. Appl. Phys. 459276

[202] Mishra L N, Shibata K, Ito H, Yugami N and Nishida Y 2004 IEEE Trans. Plasma Sci. 321727

[203] Matsushita A, Nagai M, Yamakawa K, Hiramatsu M, Sakai A, Hori M, Goto T and Zaima S 2004 Jap. J. Appl. Phys. 43424

[204] Choi B H, Kim W J, Kim Y B, Lee J H, Park J W, Kim W S and Shin D C 2008 J. Nanosci. Nanotechnol. 84999 
[205] Zhang Y-P, Liu C-J and Zhang M-H 2000 Chem. Lett. 101204

[206] Chandrashekar A, Lee J-S, Lee G S, Goeckner M J and Overzet L J 2006 J. Vac. Sci. Technol. A 241812

[207] Nozaki T, Karatsu T, Ohnishi K and Okazaki K 2010 Carbon 48232

[208] Shirai H, Kobayashi T and Hasegawa Y 2005 Appl. Phys. Lett. 87143112

[209] Kumar P 2010 Nanoscale Res. Lett. 51367

[210] Atkinson A 1985 Rev. Modern Phys. 57437

[211] Levchenko I, Ostrikov K, Mariotti D and Švrček V 2009 Carbon 472379

[212] Levchenko I, Ostrikov K and Mariotti D 2009 Carbon 47313

[213] Li-Fang D, Ya-Feng H, Zeng-Qian Y and Zhi-Fang C 2003 Chin. Phys. Lett. 201524

[214] Eden J G, Park S-J, Ostrom N P and Chen K-F 2005 J. Phys. D: Appl. Phys. 381644

[215] Becker K H, Schoenbach K H and Eden J G 2006 J. Phys. D: Appl. Phys. 39 R55

[216] Chai J, Li B, Kwok D Y 2005 Appl. Phys. Lett. 86034107

[217] Akinwande D, Patil N, Lin A, Nishi Y and Philip Wong H-S 2009 J. Phys. Chem. C 1138002

[218] Nessim G D, Hart A J, Kim J S, Acquaviva D, Oh J, Morgan C D, Seita M, Leib J S, and Thompson C V 2008 Nano Lett. 83587

[219] Danielson D T, Sparacin D K, Michel J and Kimerling L C 2006 J. Appl. Phys. 100 083507

[220] Pierre-Louis O, Chame A and Saito Y 2007 Phys. Rev. Lett. 99136101

[221] Arnoult G, Cardoso R P, Belmonte T and Henrion G 2008 Appl. Phys. Lett. 93191507

[222] Arnoult G, Belmonte T and Henrion G 2010 Appl. Phys. Lett. 96101505

[223] Bowden N, Terfort A and Carbeck Whitesides G M 1997 Science 276233

[224] Erdem Alaca B, Sehitoglu H and Saif T 2004 Appl. Phys. Lett. 844669

[225] Mozetič M, Cvelbar U, Sunkara M K and Vaddiraju S 2005 Adv. Mater. 172138 
[226] Fu Y Chen J and Zhang H 2001 Chem. Phys. Lett. 350491

[227] Chen Z, Cvelbar U, Mozetič M, He J and Sunkara M K 2008 Chem. Matter. 203224

[228] Cvelbar U, Chen Z, Sunkara M K and Mozetič M 2008 Small 41610

[229] Dai Z R, Pan Z W and Wang Z L 2003 Adv. Funct. Mater 139

[230] Ren S, Bai Y F, Chen J, Deng S Z, Xu N S, Wu Q B and Yang S 2007 Mat. Lett. 61666 


\section{Captions}

Figure 1: Examples of DBD reactors for large area. a) dissymmetric arrangement (after Jiang et al. [44]). b) Pin-to-plate dielectric barrier discharge composed of a multi-pin power electrode (after Kyung et al. [63]). c) Similar source with an aluminium power electrode coated by alumina (after Park et al. [65]). d) Dielectric barrier with capillary holes proposed by Kyung et al. [66] to get a more uniform reactive gas distribution. Similar process with a metallic grid electrode made placed between the dielectric barrier and the substrate (after Jiang et al. [67]).

Figure 2: Examples of microplasma jets. a) Capillary with a pinched nozzle wound around by a 5-turn coil connected to a $450 \mathrm{MHz}$ UHF generator. A tungsten wire connected to a $15 \mathrm{kV}$ dc power supply is used for plasma ignition (After Shimizu et al. [46]). b) Capillary with a pinched nozzle wound around by a 20-turn coil (After Chandra Bose et al. [72] and Shimizu et al. [70]). c) Capillary with wire. The UHF signal is applied on a patch antenna (after Mariotti et al. [40]). d) Additional annular nozzle used for etching (after Ichiki et al. [16]). e) Capillary with wire used as an antenna (after Kikuchi et al. [74]).

Figure 3: Microplasmas used as component of an electric circuit where charge conduction occurs through a liquid [80]. The microplasma is formed at the surface of an electrolyte and operated as the cathode, with an immersed solid metal electrode as the anode, creating a hybrid plasma-liquid electrochemical cell. At the anode, oxidation reactions leads to dissolution of the solid metal into metal cations which were then reduced at the cathode by the microplasma to nucleate metal nanoparticles.

Figure 4: Examples of plasma torches at or not too far from thermal equilibrium. a) Plasma torches excited by microwave power supplies [81-88]. b) Plasma torches excited by dc [8991]. c) possible arrangements to introduce precursors in the dc torch. d) rf induction plasma torch. 
Figure 5: TEM images of nanoparticles synthesized in the gas phase with a microplasma reactor: (a) Ni nanoparticles grown at $2.0 \mathrm{ppm}$ nickelocene vapour concentration (in Ar), (b) $\mathrm{Ni}$ nanoparticles grown at $2.6 \mathrm{ppm}$ nickelocene vapour concentration (in $\mathrm{Ar}$ ), (c) $\mathrm{Fe}$ nanoparticles grown at $1.2 \mathrm{ppm}$ ferrocene vapour concentration (in $\mathrm{Ar}$ ) and (d) $\mathrm{Ni}_{0.27} \mathrm{Fe}_{0.73}$ nanoparticles grown at a total metallocene vapour concentration of $2.2 \mathrm{ppm}$ (in Ar). ([80] Reproduced with permission from Plasma Sources Science and Technology, Institute of Physics Publishing)

Figure 6: a) Production of a hypersonic jet of nanoparticles with two rooms operating at different pressures (see e.g. $[16,74,162,203])$. b) Principle of the xerography process. The plasma is used only as a source for producing nanoparticles. The charged particles are then deflected by the high voltage applied to a patterned electrode to come crashing onto the substrate, thus replicating the pattern (see e.g. [172]).

Figure 7: Example of localized nano-deposits produced by different methods. From left to right: "Tower" of tungsten oxide deposited by wire spraying ([71] - Reproduced with permission from Surface and Coatings Technology, Elsevier), “Tower” of SiC nanoparticles deposited by focused particle beam on a stationary substrate ([46] - Reproduced with permission from Plasma Phys. Control. Fusion, IOP) and "Tower" of hydrocarbon deposited by micro-jet CVD ([116]) - Reproduced with permission from Thin Solid Films, Elsevier).

Figure 8: Fluidized bed process for coating nanoparticles. Aggregates of nanoparticles of a hundred nanometers are disaggregated by using a vibrating device to defeat the forces of inter-particle cohesion. The powders are fluidized then pass through a plasma where they are covered, filtered in a cyclone and fed back into the process (see e.g. [60]).

Figure 9: SEM images of the carbon nanotubes grown with an AAO template. a) A top-view (some carbon nanotubes appeared at the surface). b) A cross-sectional view. ([183] Reproduced with permission from Diamond and Related Materials, Elsevier) 
Figure 10: Example of a method based on the use of templates (see e.g. [146]). The pores of an anodized alumina plate (Anodic Aluminum Oxide for AAO) are used to grow carbon nanowires. First, the pores of the AAO template are widened by chemical etching in aqueous phosphoric acid. Second, a small amount of Fe-Co catalytic particles are electrodeposited into the template pores. Third, $\mathrm{CH}_{4}$ and $\mathrm{H}_{2}(1: 10)$ are fed into the reactor at a total feed rate of 22 $\mathrm{ml} \mathrm{min}{ }^{-1}$. The corona discharge is pulsed for $10 \mathrm{~min}$ with a high voltage generator operating at $2800 \mathrm{~V}$ and $50 \mathrm{kpps}$ with the power of $10 \mathrm{~W}$. Fourth, alumina is dissolved in a solution of sodium hydroxide to get the carbon nanowires standing on the surface.

Figure 11: SEM images of self-organized nanostructures grown with a microplasma system based on a patch antenna and using a microdiameter capillary. a) self-aligned Mo-oxide structures b) Carbon-based connections between Ag particles ([40] - Reproduced with permission from Applied Physics Letters, American Institute of Physics)

Figure 12: SEM images of silica cells and dots deposited with a micro-afterglow at atmospheric pressure by chemical vapour deposition using HMDSO. The stress level controls the self-organisation of these structures $[221,222]$.

Table 1: Some characteristics of microplasma jets used for localized PECVD at atmospheric pressure. 


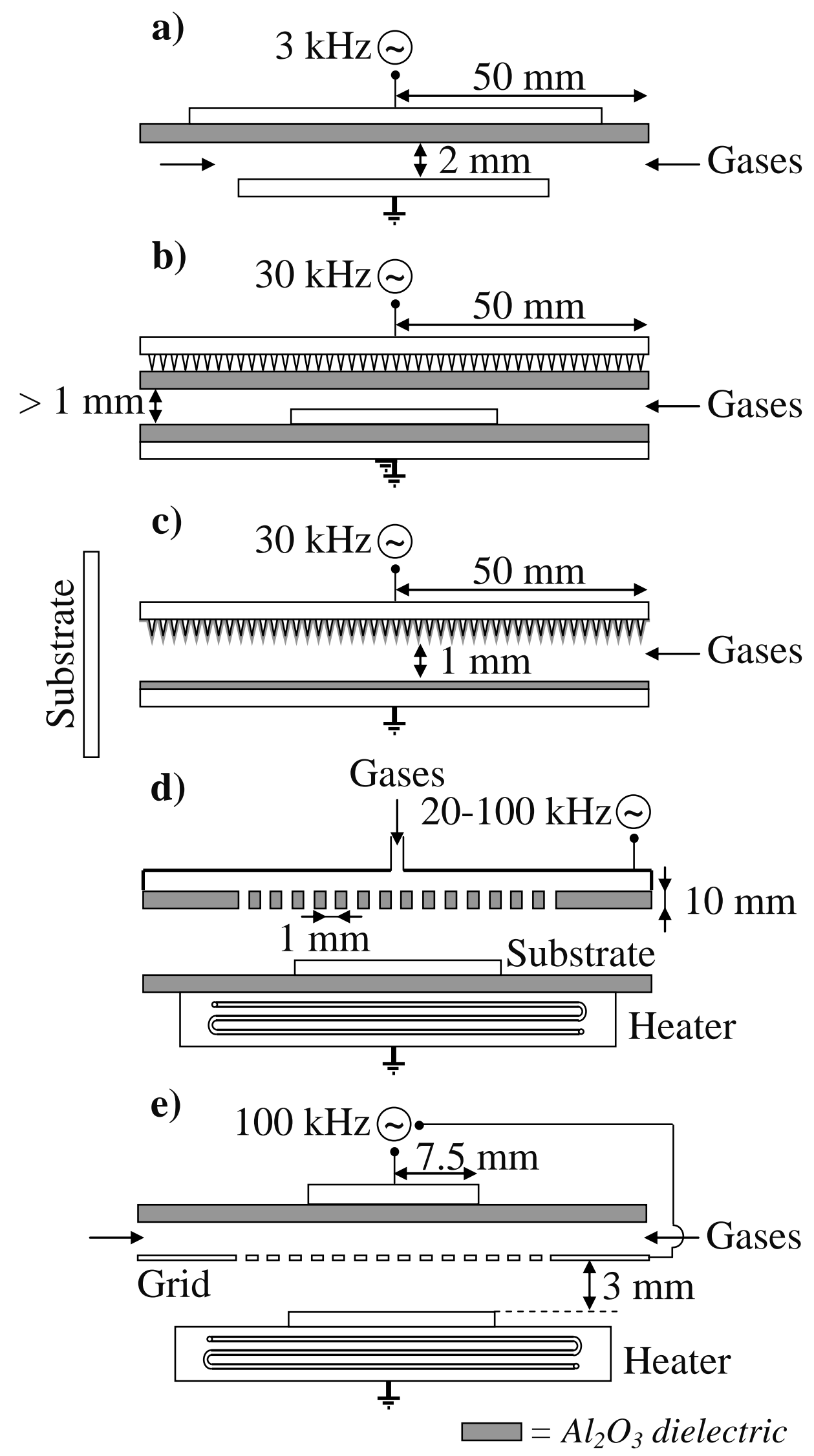

Figure 1 
a)

Gases

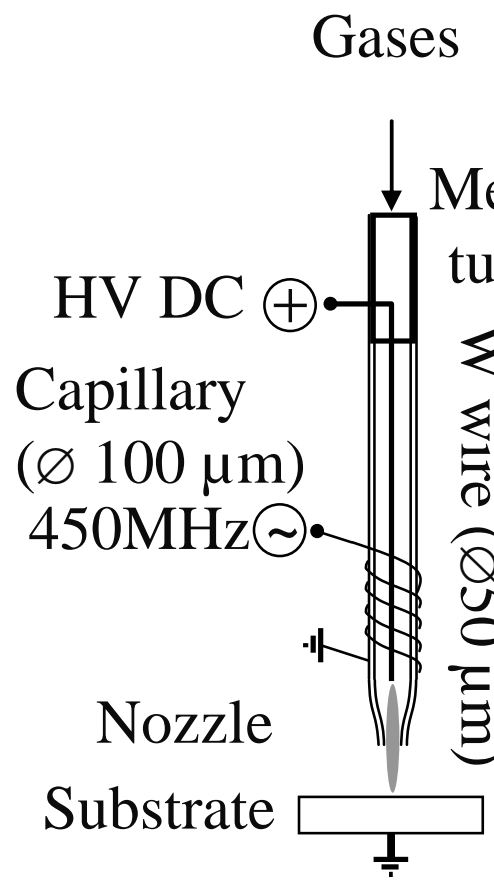

d)

Gases b)

Gases



Gases

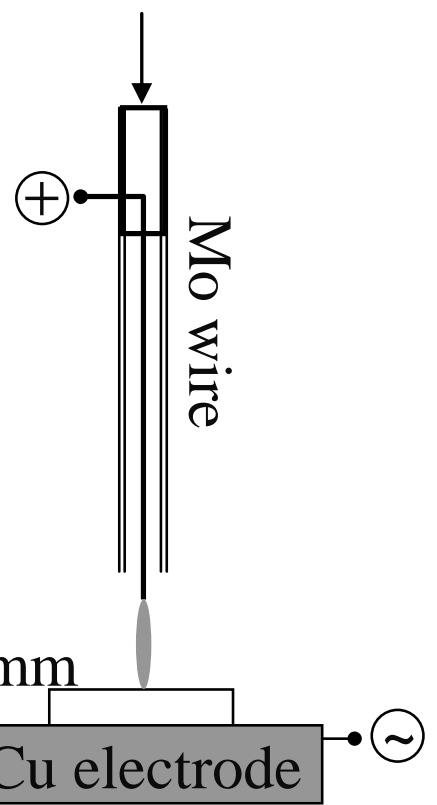

e)

Gases

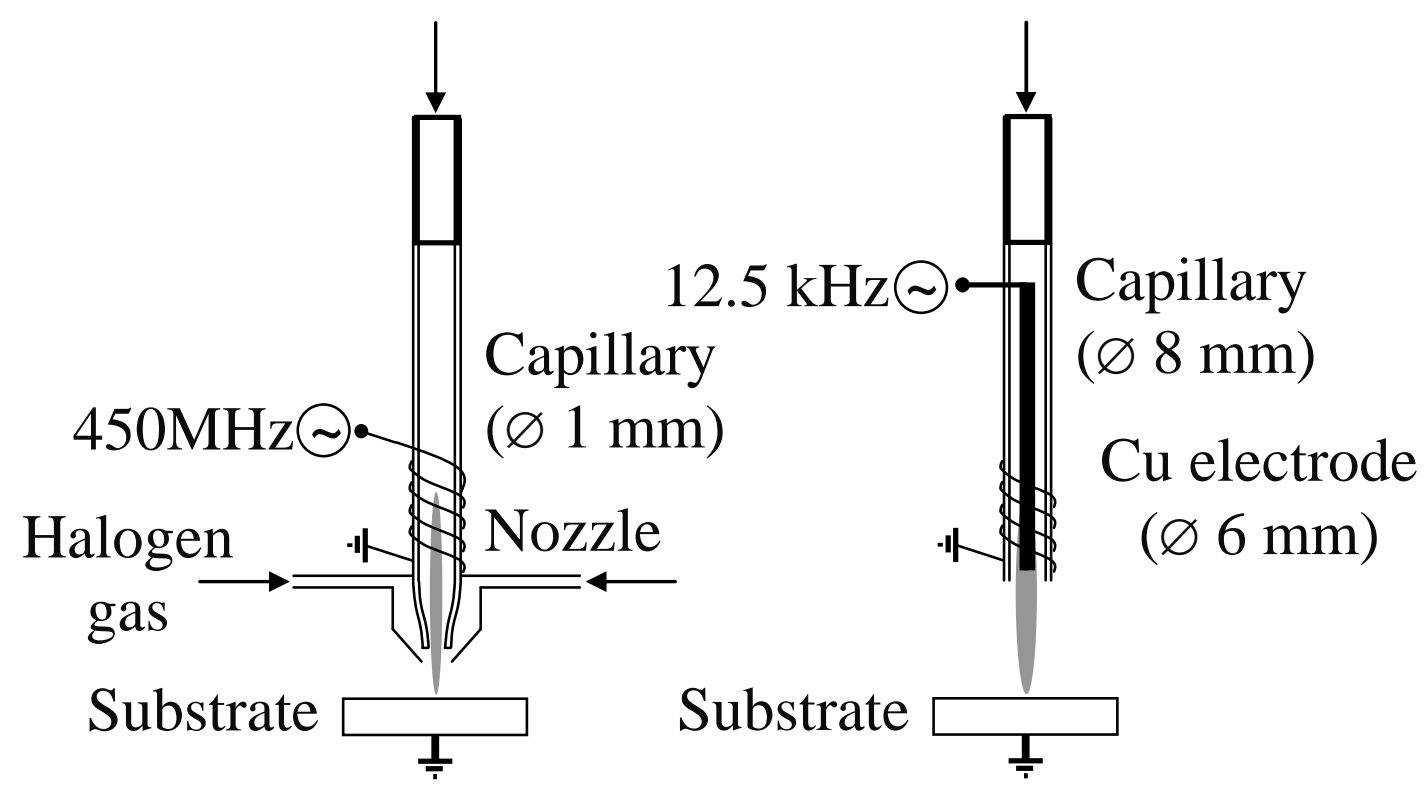

Figure 2 


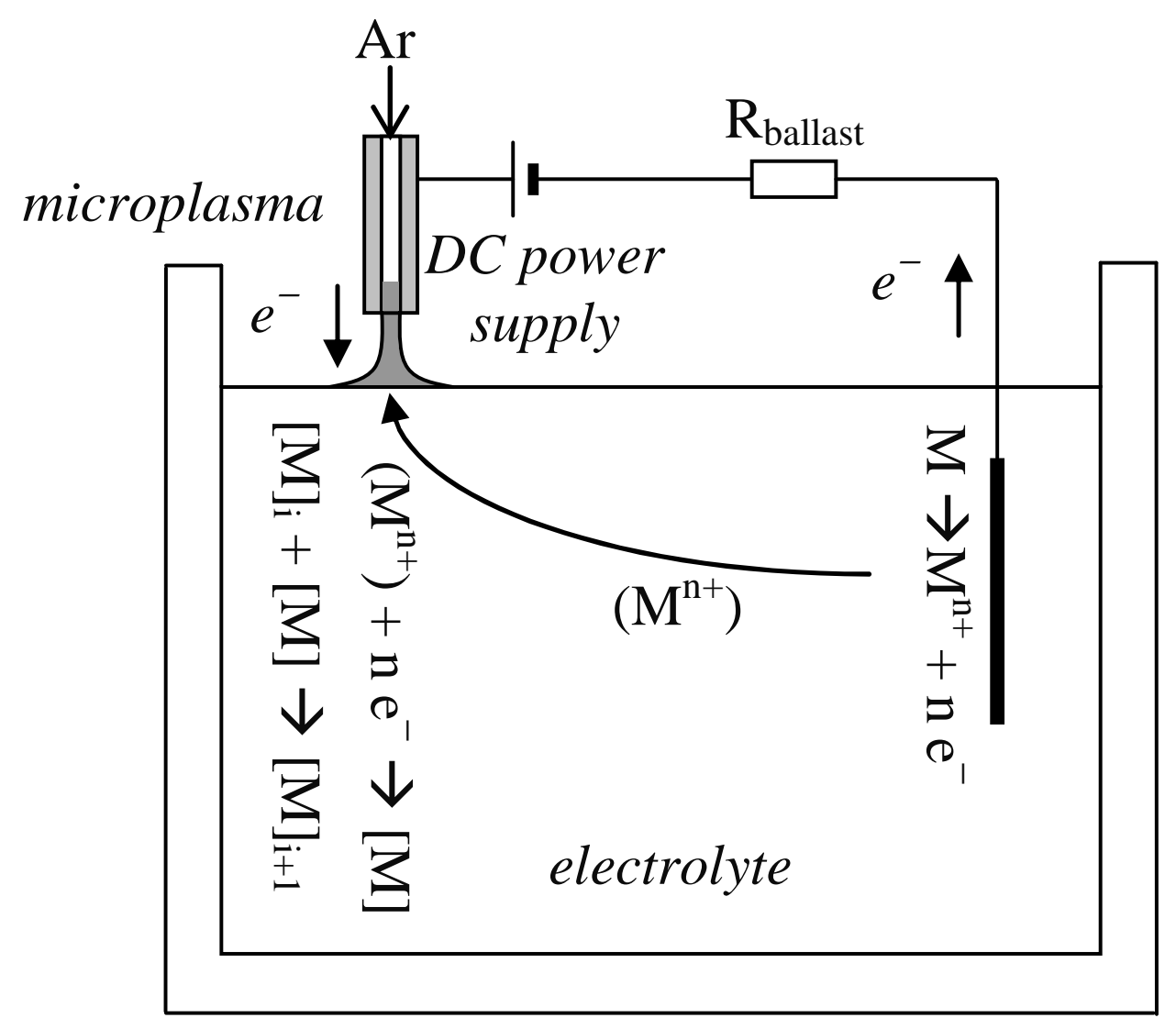

Figure 3 
a)

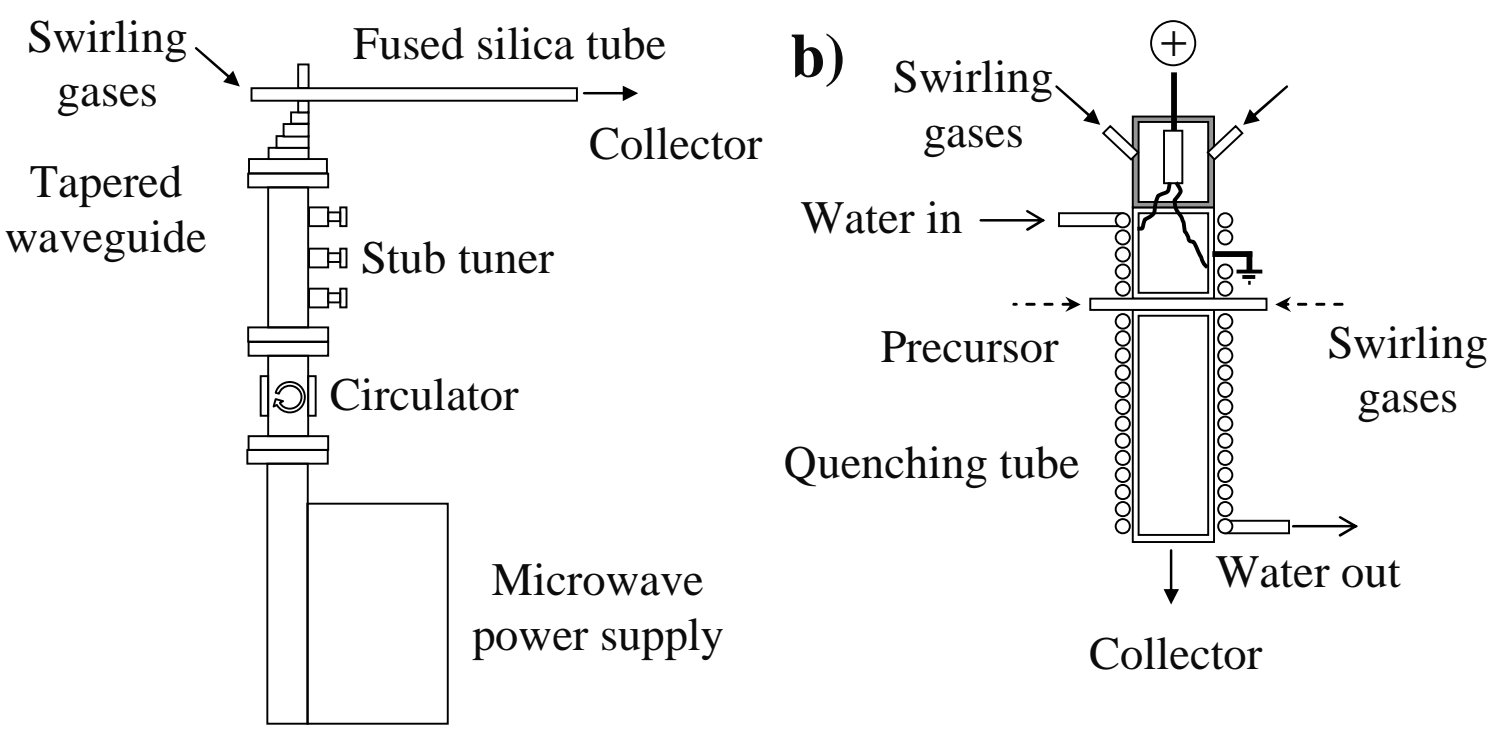

c)

d)

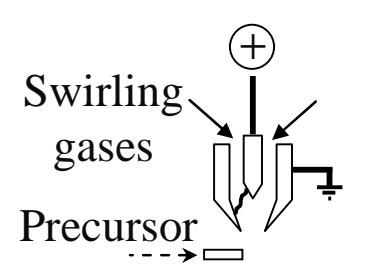

Precursor

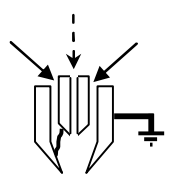

Collector

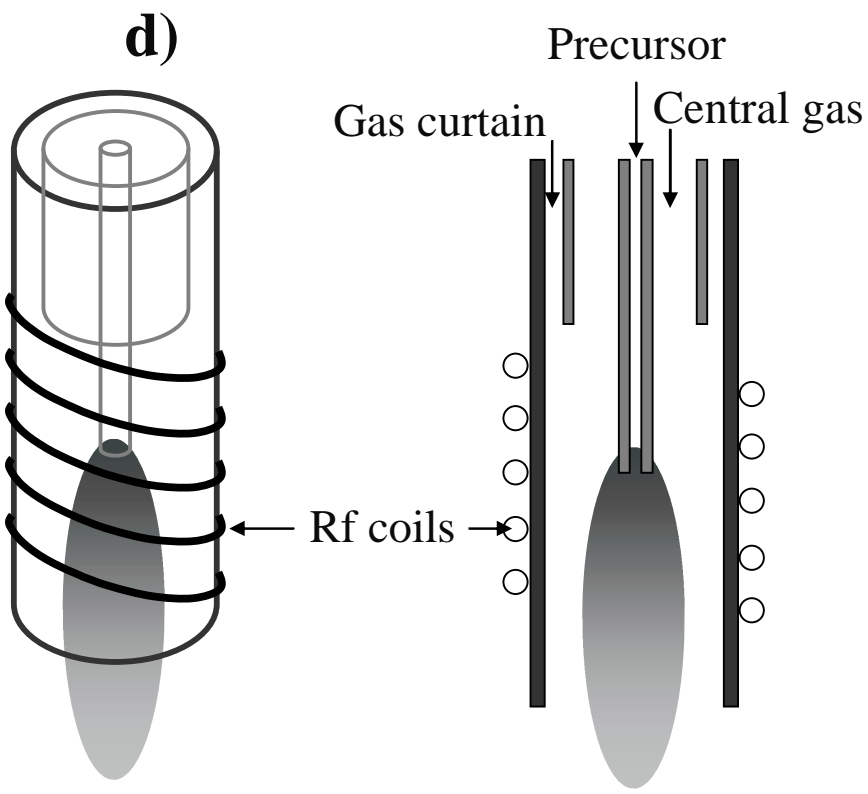

Figure 4 

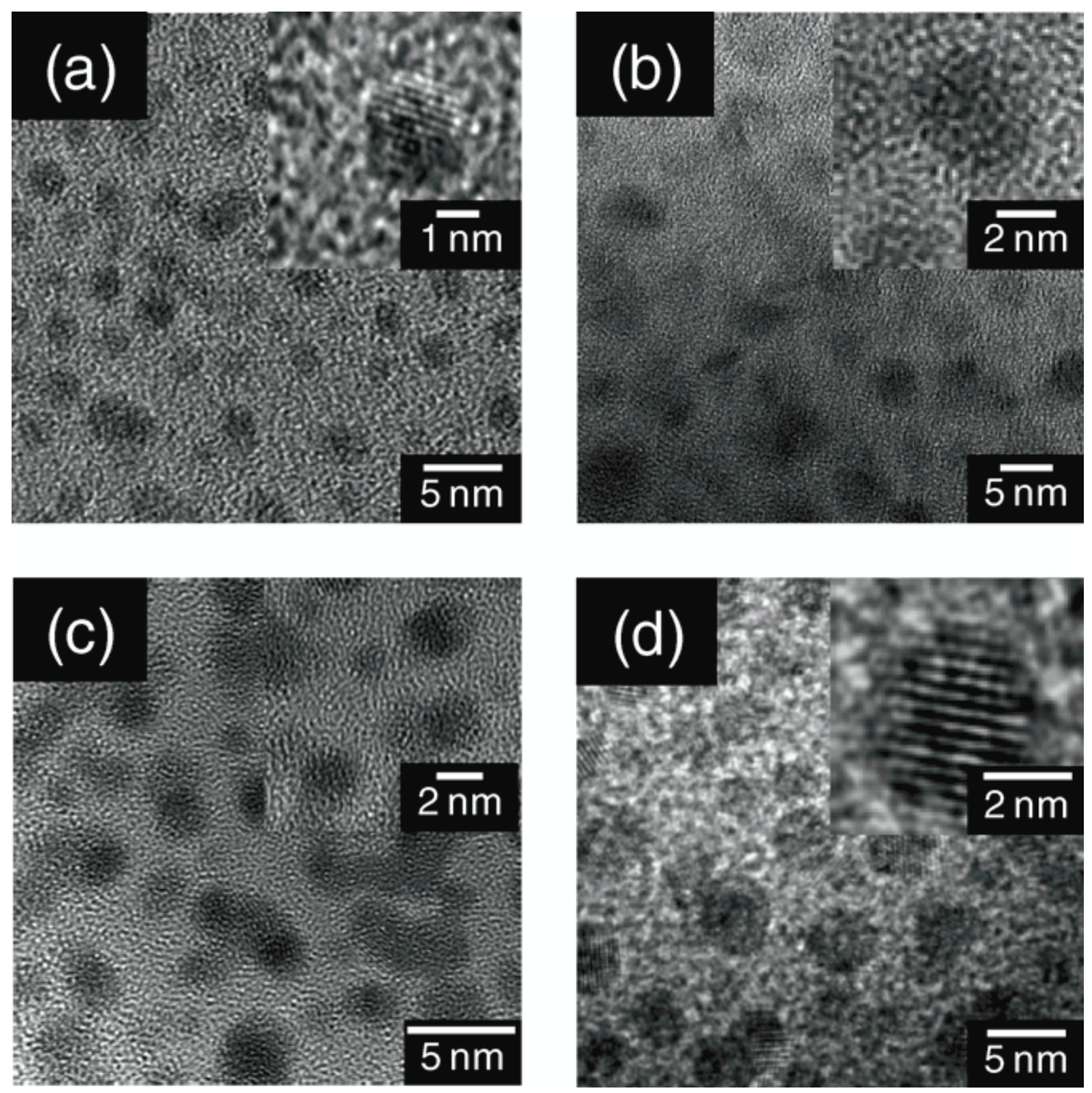

Figure 5 
a)

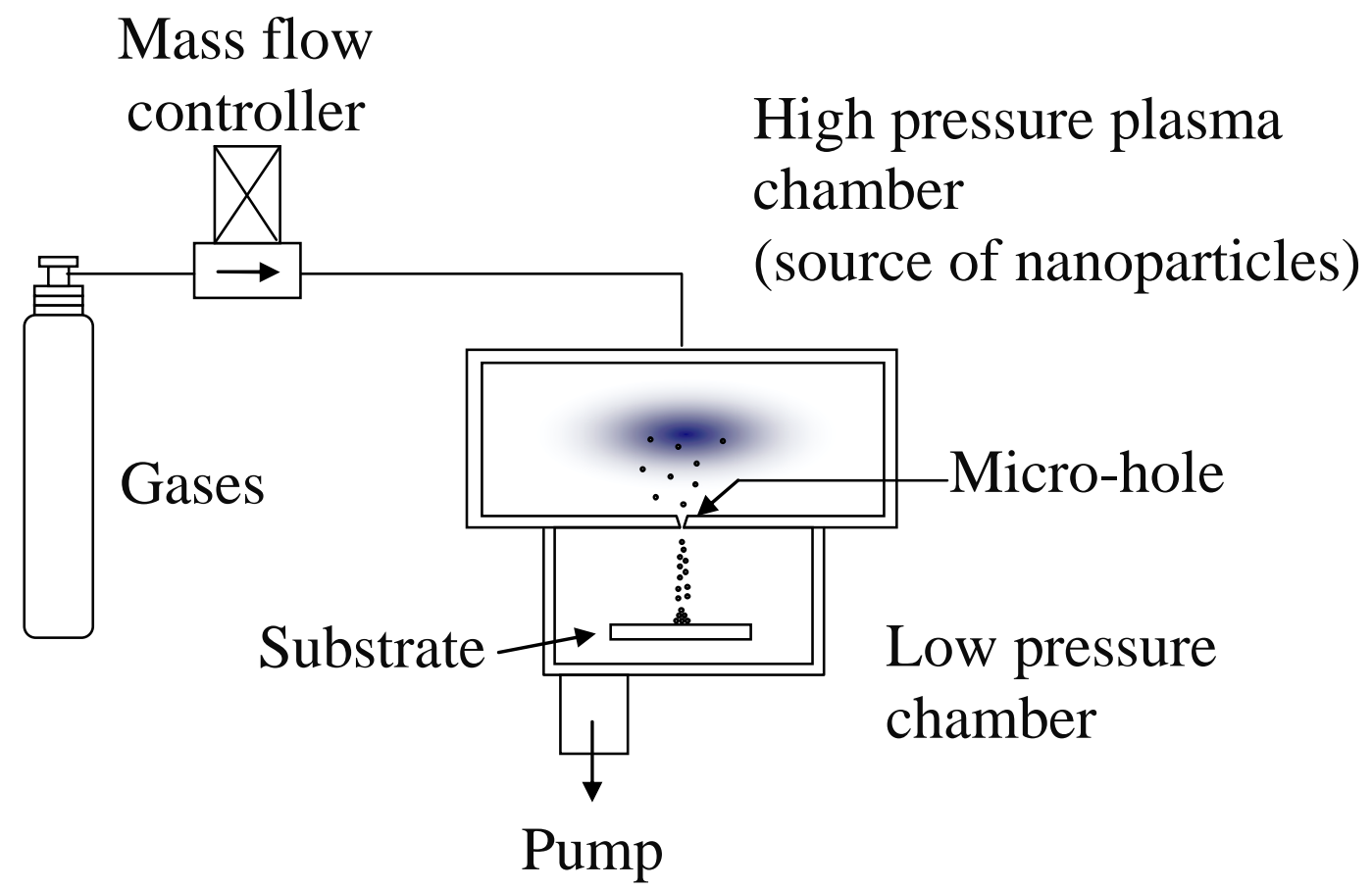

b)

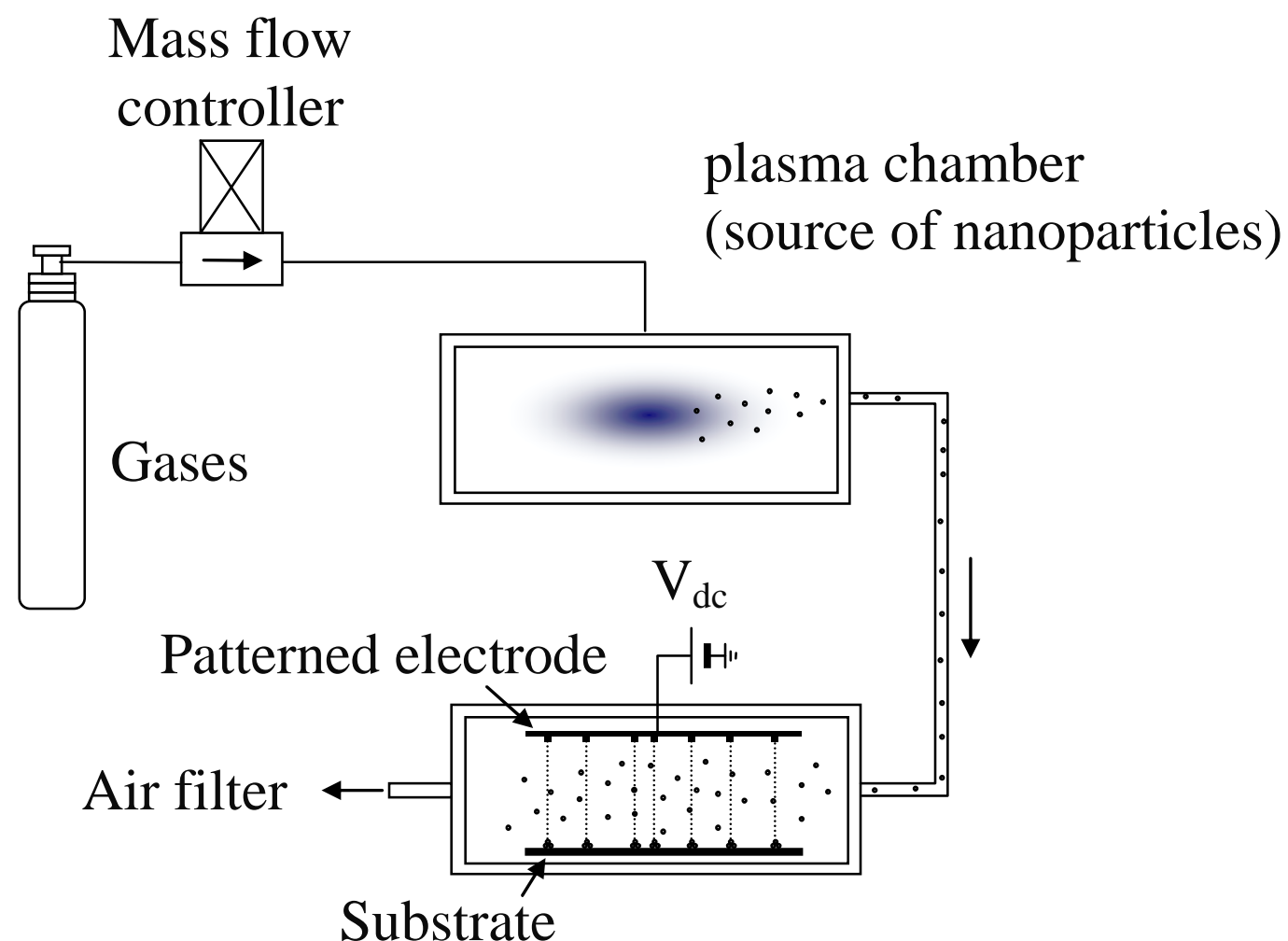

Figure 6 


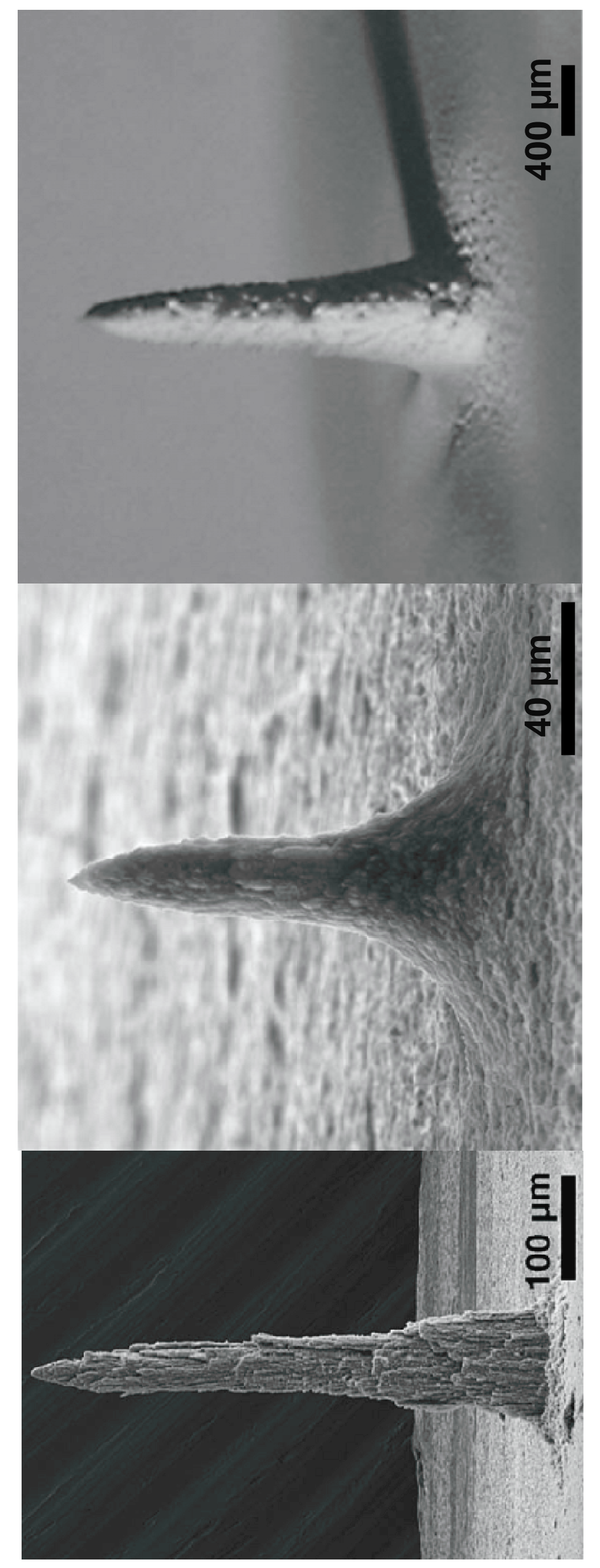




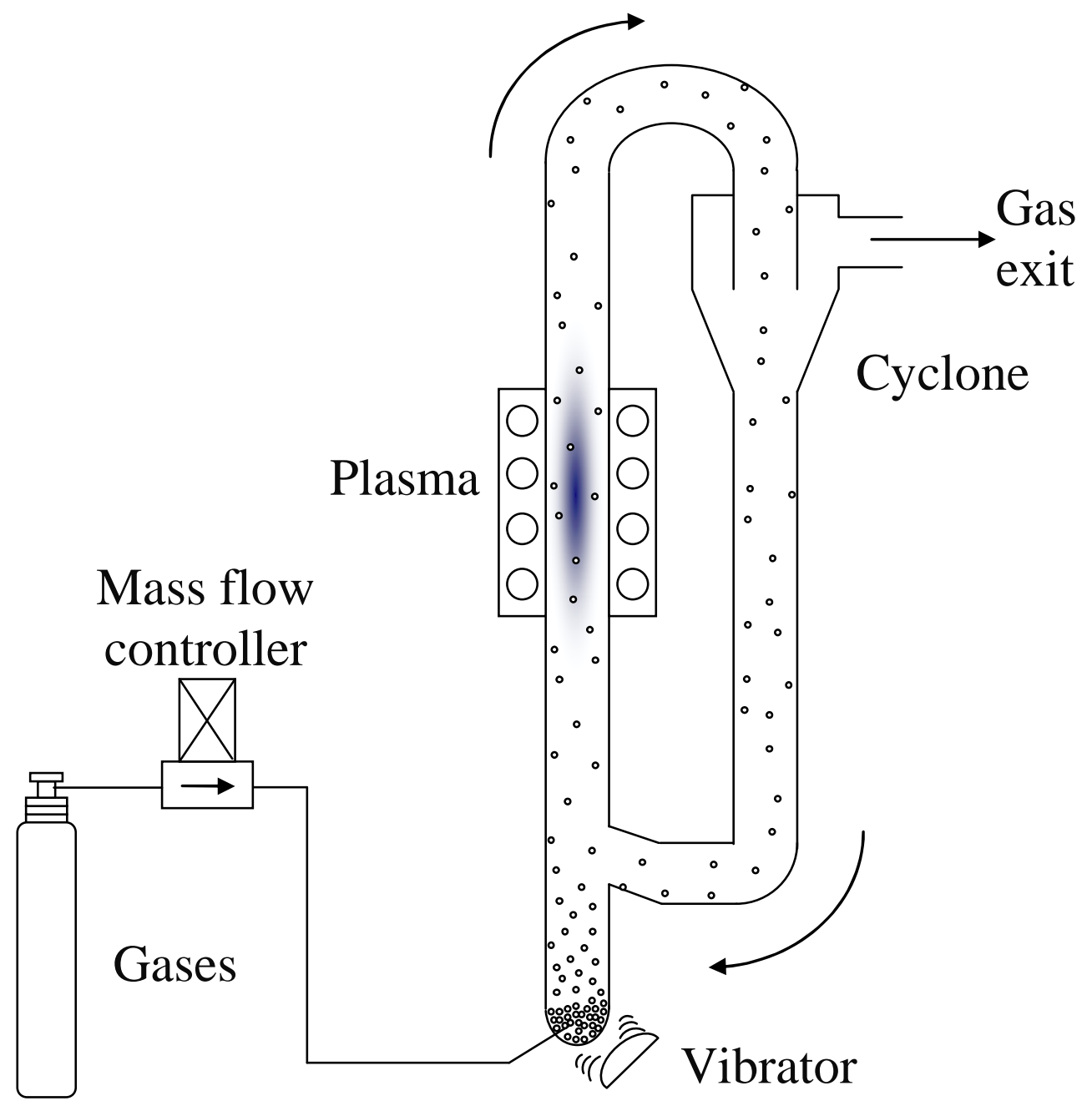

Figure 8 



Figure 9 


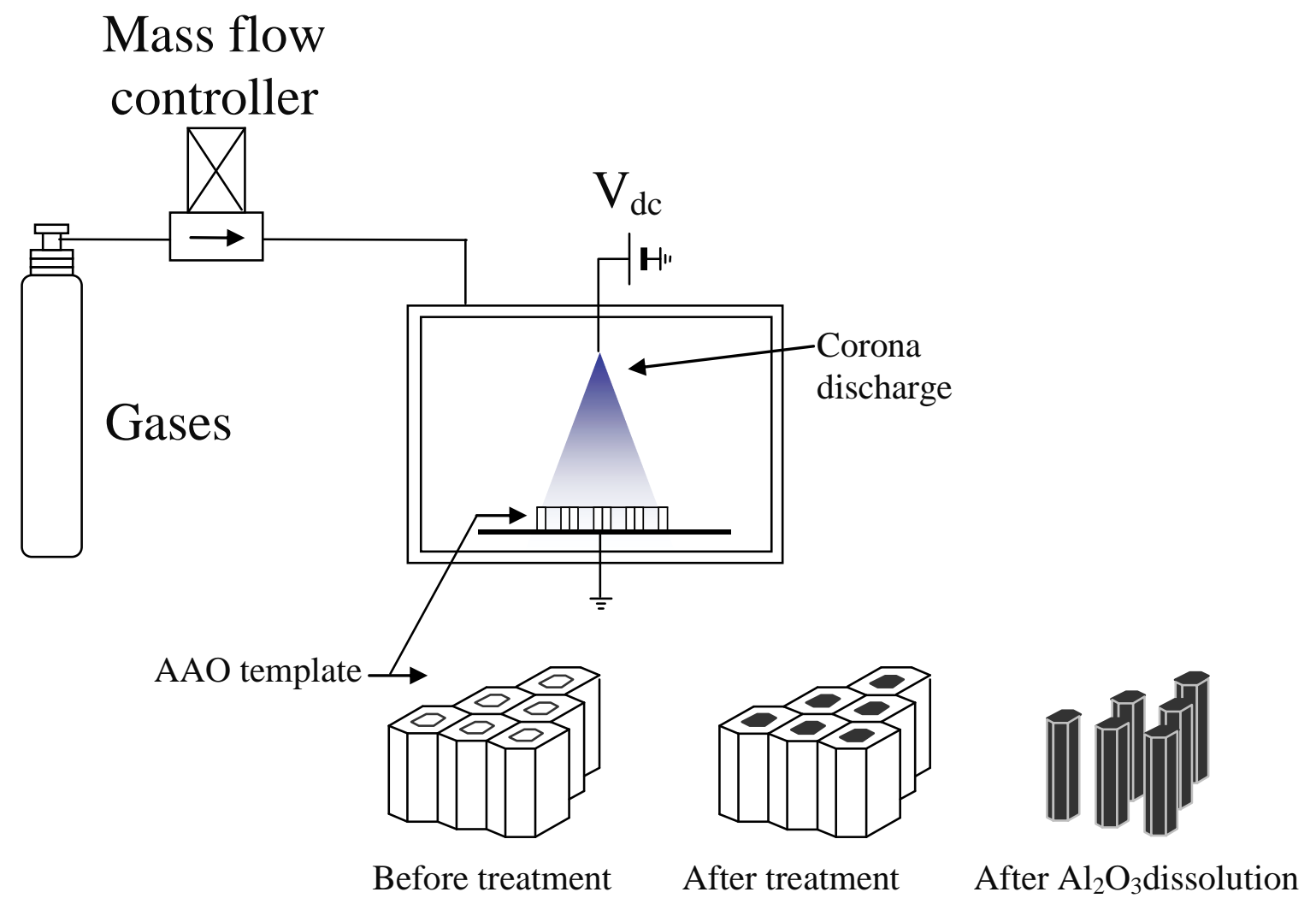

Figure 10 

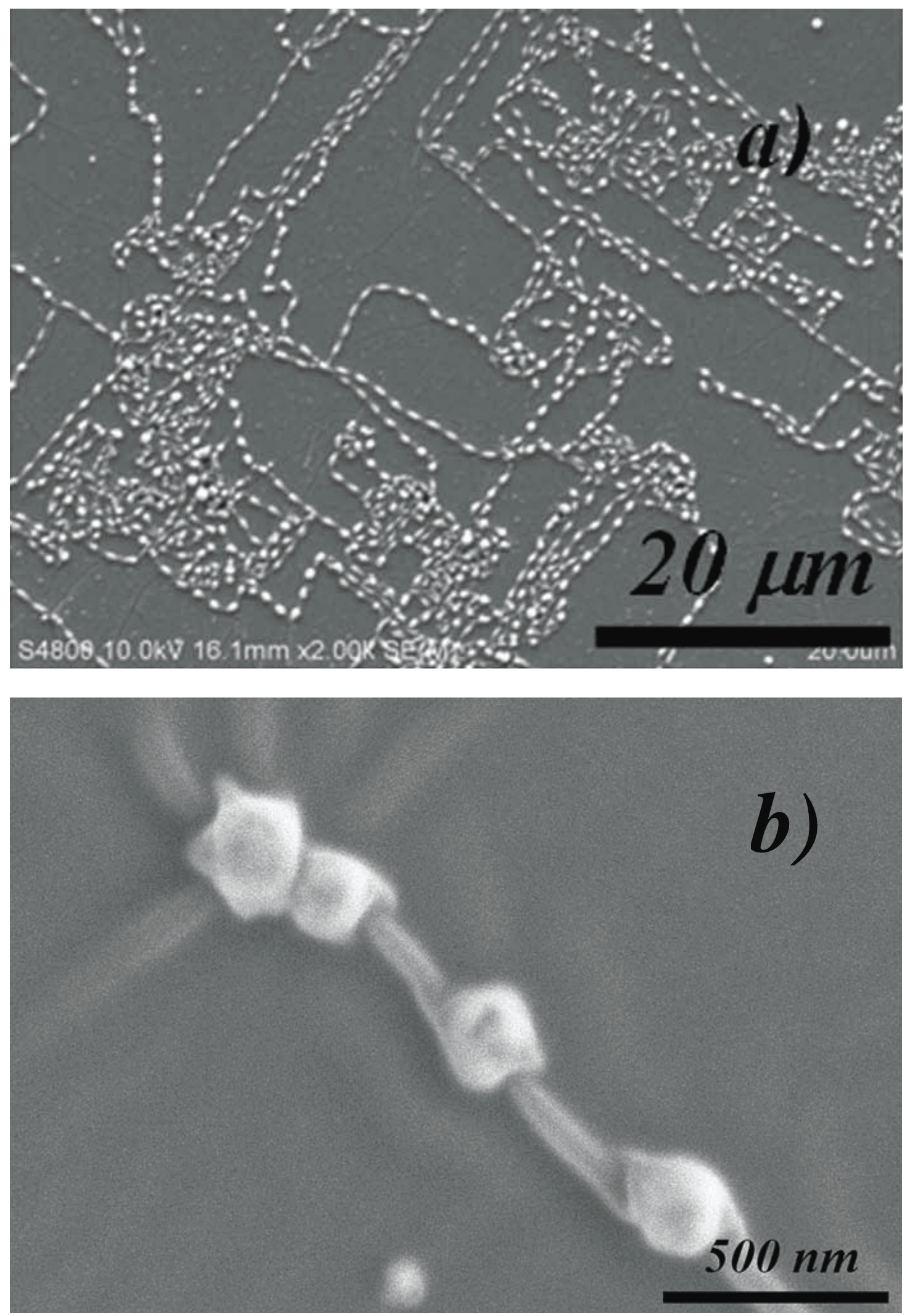

Figure 11 



Figure 12 


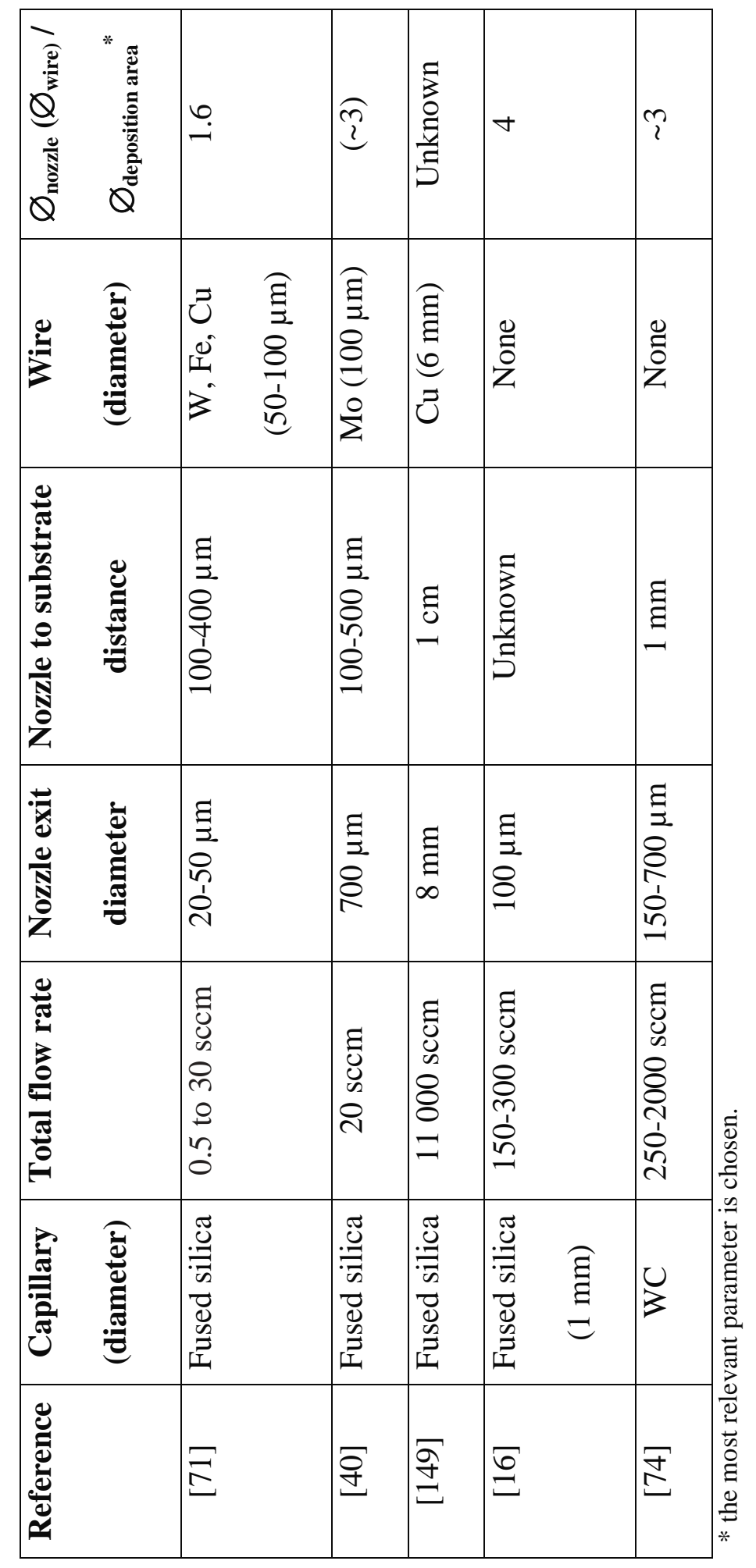

